\title{
Development of a Physiologically-Based Pharmacokinetic Model of the Rat Central Nervous System
}

\author{
Raj K. Singh Badhan ${ }^{1, \dagger}$, Marylore Chenel ${ }^{2, \star}$ and Jeffrey I. Penny ${ }^{1, *}$
}

1 Manchester Pharmacy School, the University of Manchester, Oxford Road, Manchester, M13 9PT, UK

2 EA 3809, UFR Médecine-Pharmacie, 34 Rue du Jardin des Plantes, BP 199, 86005 Poitiers, France

$\dagger$ Current address: Aston Pharmacy School, School of Life and Health Sciences, Aston University, Aston Triangle, Birmingham B4 7ET, UK; E-Mail: r.k.s.badhan@aston.ac.uk.

$\$$ Current address: Clinical Pharmacokinetics Department, Institut de Recherches Internationales Servier, 6 Place des Pléiades, F-92415 Courbevoie Cedex, France; E-Mail: marylore.chenel@fr.negrs.com.

* Author to whom correspondence should be addressed; E-Mail: Jeffrey.penny@manchester.ac.uk; Tel.: +44-0-161-275-8344; Fax: +44-0-161-275-8349.

Received: 7 November 2013; in revised form: 26 February 2014 / Accepted: 6 March 2014 / Published: 18 March 2014

\begin{abstract}
Central nervous system (CNS) drug disposition is dictated by a drug's physicochemical properties and its ability to permeate physiological barriers. The blood-brain barrier (BBB), blood-cerebrospinal fluid barrier and centrally located drug transporter proteins influence drug disposition within the central nervous system. Attainment of adequate brain-to-plasma and cerebrospinal fluid-to-plasma partitioning is important in determining the efficacy of centrally acting therapeutics. We have developed a physiologically-based pharmacokinetic model of the rat CNS which incorporates brain interstitial fluid (ISF), choroidal epithelial and total cerebrospinal fluid (CSF) compartments and accurately predicts CNS pharmacokinetics. The model yielded reasonable predictions of unbound brain-to-plasma partition ratio $\left(K \mathrm{p}_{\mathrm{uu}, \text { brain }}\right)$ and CSF:plasma ratio (CSF:Plasma $)_{u}$ using a series of in vitro permeability and unbound fraction parameters. When using in vitro permeability data obtained from L-mdrla cells to estimate rat in vivo permeability, the model successfully predicted, to within 4-fold, $K \mathrm{p}_{\text {uu,brain }}$ and CSF:Plasma $\mathrm{u}_{\mathrm{u}}$ for $81.5 \%$ of compounds simulated. The model presented allows for simultaneous simulation and analysis of both brain biophase and CSF to accurately predict CNS pharmacokinetics from preclinical drug parameters routinely available during discovery and development pathways.
\end{abstract}


Keywords: physiologically-based pharmacokinetic model; blood-brain barrier; cerebrospinal fluid; unbound fraction; brain

\section{Introduction}

Quantification of central nervous system (CNS) drug levels in brain interstitial fluid (ISF) and cerebrospinal fluid (CSF) is often achieved by complex in vivo experimental procedures, such as microdialysis. This technique has the inherent advantage of directly measuring the concentration of unbound drug in the accessible brain biophase under non-steady state and steady-state conditions [1,2], reflecting both drug influx and efflux processes acting within the CNS. To be able to quantify the brain pharmacokinetics of a compound of interest, microdialysis offers the advantage of multiple time-point sampling within the same animal, although the procedure leads to local tissue damage around the site of probe insertion $[3,4]$ and is an experimental procedure often limited to lower-species, although neuroimaging techniques, such as positron emission tomography, have been utilised in both lower- and higher-species to quantify temporal drug concentrations in brain [5]. Microdialysis and PET (positron emission tomography) are often considered the "gold-standard" for assessing (regional) brain disposition of drugs, but can be limiting due to their technical and experimental complexity, which may hinder widespread use in pre-clinical studies.

The ability to determine the relationship between systemic exposure and CNS drug disposition is an important focus for pharmaceutical industry and drug development programs. Typically, pre-clinical measurement of drug partitioning between the CNS (brain tissue and CSF components) and plasma to yield total brain-to-plasma concentration ratio, $K \mathrm{p}_{\text {brain }}$ is conducted in rodents and $K \mathrm{p}_{\text {brain }}$ is then converted to the unbound concentration ratio $\left(K \mathrm{p}_{\text {uu,brain }}\right)$ by multiplication with plasma unbound drug fraction ( $f \mathrm{u}_{\mathrm{p}}$ ) (Equation (1) $C$, total concentration; $C_{\mathrm{u}}$, unbound concentration; $V_{\mathrm{u}}$, unbound brain volume of distribution) [6]. The steady-state unbound brain-to-plasma ratio $\left(K \mathrm{p}_{\text {uu,brain }}\right)$ (Equation (2)) or steady-state cerebrospinal fluid-to-plasma concentration ratios $\left(\mathrm{CSF}_{\mathrm{u}}: \mathrm{Plasma}_{\mathrm{u}}\right.$ and CSF:Plasma ${ }_{\mathrm{u}}$ ) (Equations (3) and (4) respectively) are routinely used to represent CNS disposition of pharmacologically active drugs within the CNS.

$$
\begin{gathered}
K \mathrm{p}_{\text {brain }}=\frac{C_{\text {brain }}}{C_{\text {plasma }}} \text { and } K \mathrm{p}_{\text {uu,brain }}=\frac{K \mathrm{p}_{\text {brain }}}{V \mathrm{u}_{\text {brain }} \times f \mathrm{u}_{\mathrm{p}}} \\
\mathrm{Kp}_{\text {uu,brain }}=\frac{\int_{0}^{\infty} C_{\mathrm{u}} \text { brain } \times \mathrm{dt}}{\int_{0}^{\infty} C_{\mathrm{u}} \text { plasma } \times \mathrm{dt}}=\frac{\mathrm{AUC}_{\mathrm{u}, \text { brain }}}{\mathrm{AUC}_{\mathrm{u}, \text { plasma }}} \\
\mathrm{CSF}_{\mathrm{u}}: \text { Plasma }_{\mathrm{u}}=\frac{\int_{0}^{\infty} C_{\mathrm{u}} \mathrm{csf} \times \mathrm{dt}}{\int_{0}^{\infty} C_{\mathrm{u}} \text { plasma } \times \mathrm{dt}}=\frac{\mathrm{AUC}_{\mathrm{u}, \text { csf }}}{\mathrm{AUC}_{\mathrm{u}, \text { plasma }}} \\
\mathrm{CSF}: \text { Plasma }_{\mathrm{u}}=\frac{\int_{0}^{\infty} C \operatorname{csf} \times \mathrm{dt}}{\int_{0}^{\infty} C_{\mathrm{u}} \text { plasma } \times \mathrm{dt}}=\frac{\mathrm{AUC}_{\mathrm{csf}}}{\mathrm{AUC}_{\mathrm{u}, \text { plasma }}}
\end{gathered}
$$

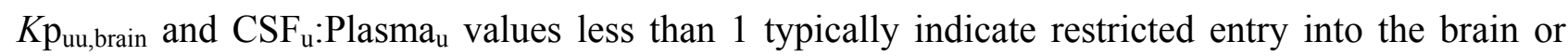
CSF-compartments, predominantly a result of efflux or uptake transport proteins respectively, whereas 
values greater than 1 indicate unrestricted entry into the brain or CSF, facilitated by active transport. Values close to unity indicate predominantly passive transport of drug.

A major factor in successful delivery of drugs to the CNS is circumvention of physiological barriers. The ATP-binding Cassette (ABC) efflux transporters P-glycoprotein [7], breast cancer resistance protein (BCRP) and several multidrug resistance-associated proteins (MRPs) are expressed at the BBB (blood-brain barrier) [7-10]. Mdrl knockout studies in mice reveal that P-glycoprotein significantly influences CNS disposition of both non-CNS targeted and CNS targeted therapeutics including amitriptyline, nortriptyline [11], olanzipine [12], buspirone, chlorpromazine, fluvoxamine, risperidone, zolpidem [13] and fexofenadine [14]. Similar reports of altered brain penetration of imatinib [15], oseltamivir [16] and genistein [17] have been reported in breast cancer resistance protein knockout mice. In addition to BBB-associated ABC transporters influencing CNS drug disposition, expression of highly restrictive tight junction complexes at the BBB (the transcellular electrical resistance is reported to be between 1000 and $1800 \Omega \mathrm{cm}^{2}$ [18-20]) results in only limited passive diffusion of hydrophilic, low molecular weight ( $<400 \mathrm{Da})$ compounds [21] across the BBB into the CNS.

The blood-cerebrospinal fluid barrier (BCSFB) also can regulate entry of compounds into the CNS [22] and is an important consideration when describing CNS drug disposition. The BCSFB is located next to the choroidal epithelium, a continuous single layer of polarized epithelial-like cells, possessing tight junctions [23], which line the surface of the choroid plexuses. There are important physiological differences between the $\mathrm{BBB}$ and $\mathrm{BCSFB}$. In vitro measurements suggest the transcellular electrical resistance of the BCSFB is approximately 10- to 15-fold less than that of the BBB, at $80-100 \Omega \mathrm{cm}^{2}$ [18-20]. Unlike the BBB, the choroidal epithelium possesses extensive microvilli and studies suggest the total surface area of the choroid plexuses may be 10 -fold greater than previous estimates, placing the surface area within a similar order of magnitude to that of the BBB [24-28], and resulting in in vivo BCSFB clearance measurements, per gram of brain, which may be similar to or greater than that at the BBB [29]. However, both P-glycoprotein [30,31] and BCRP [31] have been reported to be expressed at the apical plasma membrane of the choroidal epithelium, and have the potential to transport drugs from the choroidal epithelium into the ventricular CSF. It is therefore important that the differential transport directionalities at the BBB and BCSFB sites are taken into consideration when attempting to predict drug disposition within the CNS.

Efflux transporter proteins at the BBB will therefore limit penetration of compounds into the brain and impact on CNS disposition, whereas efflux transports at the BCSFB will act to potentially enhance the accumulation of compounds in the CSF. Consequently, for highly effluxed drugs there is often a discrepancy between the effects of efflux at the BBB (influencing $K p_{u u, b r a i n}$ ) and the BCSFB (influencing $\mathrm{CSF}_{\mathrm{u}}: \mathrm{Plasma}_{\mathrm{u}}$ ) [32-34].

Clearly, the measurement of brain unbound concentrations would provide a better indicator for assessing CNS disposition, but microdialysis is not an option routinely employed, pre-clinically. However, determination of the extent of non-specific brain tissue binding $\left(f u_{\text {brain }}\right)$, using brain slice and brain homogenate methods, is utilised to drive forward an understanding of overall brain drug penetration. Thus, an understanding of the role of drug transporter proteins at both the BBB and BCSFB coupled with knowledge of brain tissue binding is crucial in order to more effectively predict CNS drug disposition $\left(\mathrm{Kp}_{\mathrm{uu}, \text { brain }}\right.$ and $\left.\mathrm{CSF}_{\mathrm{u}}: \mathrm{Plasma}_{\mathrm{u}}\right)$ and facilitate early pharmacokinetic predictions and selection of compounds for further development $[13,35]$. 
A key paradigm in CNS drug development is the prediction of brain accumulation of candidate compounds [36,37]. The application of physiologically-based pharmacokinetic modeling provides an approach to mechanistically incorporate routinely determined in vitro data, such as drug permeability and protein binding, into a pharmacokinetic model capable of estimating CNS drug disposition. There is, however, a significant lack of predictive models capable of quantifying CNS drug disposition. In non-physiological models, the CNS is described by either a 1-compartment model (representing brain) or a 2-compartment model (representing brain interstitial fluid and brain intravascular fluid (IVF)) with such models often being used in conjunction with brain microdialysis data to describe CNS drug disposition [2,3]. Semi-physiological models have also been proposed that attempt to mechanistically describe drug disposition within the brain [38-42] but are nonetheless hindered by the requirement for some a priori clinically-derived input data.

Recently Ball et al. [43] described the development of a whole-body physiologically based pharmacokinetic (PBPK) model for the prediction of unbound drug concentration-time profiles in the rat brain, utilising a mechanistic approach to described drug transfer across the blood-brain barrier. Despite this, there is a lack of fully mechanistic CNS PBPK models employed to describe CNS pharmacokinetics, which limits the application of such models to the prediction of CNS drug disposition.

A key challenge in predicting CNS drug disposition is the extrapolation of cell line-derived permeability data obtained in vitro to an in vivo permeability metric. In vitro permeability data derived from immortalised non-cerebral and cerebral cell lines [44-49] has been used previously to assess BBB penetration [50-52] despite clear phenotypic differences (e.g., efflux transporter expression profile, enzyme activity) between many of the cell lines used, e.g., Caco-2 (human colorectal adenocarcinoma cell line) and MDCK (Madin-Darby canine kidney cells), and blood-brain barrier endothelial cells.

Recently, positive correlations between drug permeability assessed in the L-mdrla cell line (the LLC-PK1 porcine kidney cell line transfected with murine P-glycoprotein) and the extent of CNS drug disposition $\left(K \mathrm{p}_{\text {brain }}\right)$ have been reported [53-55]. Of fundamental importance to this correlation is P-glycoprotein protein abundance in transfected cell lines compared to brain microvascular endothelial cells within the BBB. Recent progress in the quantification of absolute expression levels of P-glycoprotein in brain capillaries has estimated total mdrla protein abundance in mouse brain capillaries to be $14.1 \mathrm{fmol} / \mu \mathrm{g}$ protein [56] and rat brain capillaries to be $19.1 \mathrm{fmol} / \mu \mathrm{g}$ protein [57] which is very similar to the in vitro protein abundance in L-mdrla cells, $15.2 \mathrm{fmol} / \mu \mathrm{g}$ protein $[54,55]$, but higher in comparison to that measured in human brain capillaries (6.06 fmol/ $\mu \mathrm{g}$ protein) [54]. Such findings suggest data derived from L-mdrla cells could be incorporated into predictive physiologically-based pharmacokinetic models and may prove useful in assessing CNS drug disposition for P-glycoprotein substrates.

In the present study we describe a predictive, physiologically-based pharmacokinetic model of the rat CNS which incorporates discrete brain and CSF components and is able to predict brain-to-plasma and CSF-to-plasma ratios using in vitro permeability parameters and drug protein/tissue binding data. In addition, we also developed a mouse whole-body PBPK model which, when populated with mouse physiological parameters and L-mdrla cell-derived data, allowed prediction of mouse $K \mathrm{p}_{\mathrm{uu} \text {,brain }}$ and CSF:Plasma ${ }_{\mathrm{u}}$ (see Supplementary Information). 


\section{Experimental Section}

\subsection{Development of a Whole-Body Physiologically Based Pharmacokinetic (PBPK) Model}

\subsubsection{Model Development}

A whole-body PBPK model was constructed in Matlab (version 8.1). The model consisted of the following compartments: lung, bone, brain vascular space (V), brain extravascular space (EV), cerebrospinal fluid (CSF), choroid plexus (CP), heart, kidney, liver, muscle, adipose, skin, pancreas, gut, spleen, and arterial and venous blood (Figure 1). All tissue compartments were considered well stirred (perfusion limited) except for CNS-related compartments (Figure 1).

Figure 1. (A) Whole-body physiologically based pharmacokinetic (PBPK) model. CL: Clearance; CSF: Cerebrospinal fluid; and (B) Brain and CSF compartments. $\mathrm{V}$ : vascular compartment; $\mathrm{EV}$ : extra-vascular compartment; $\mathrm{CL}_{\text {passive }}$ : passive clearance; $\mathrm{CL}_{\text {active: }}$ active efflux clearance.

(A)

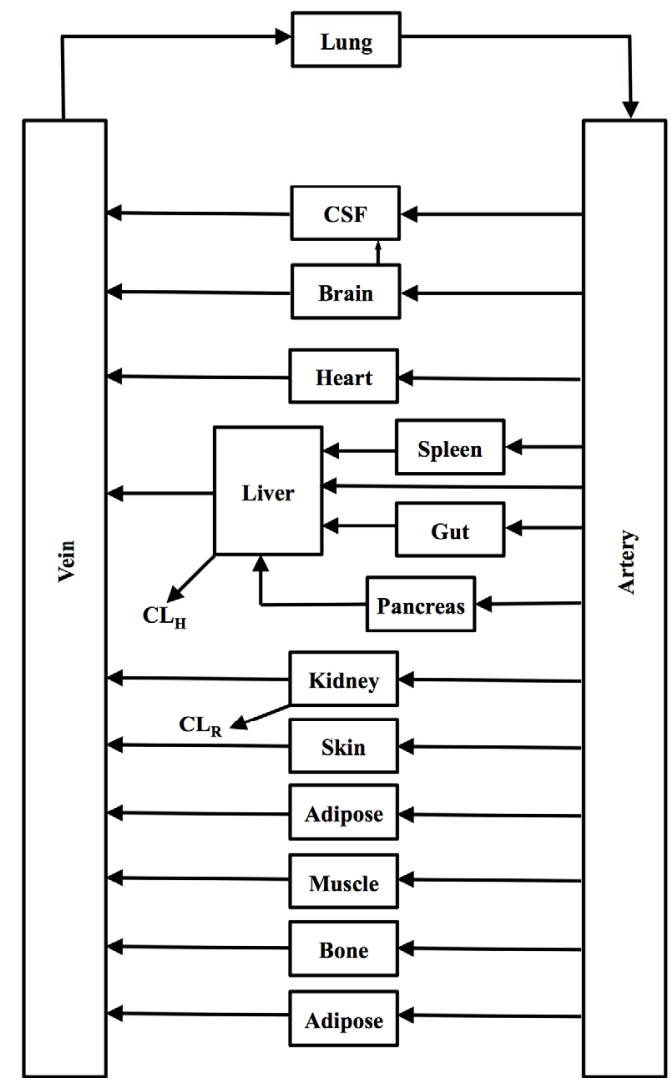

(B)

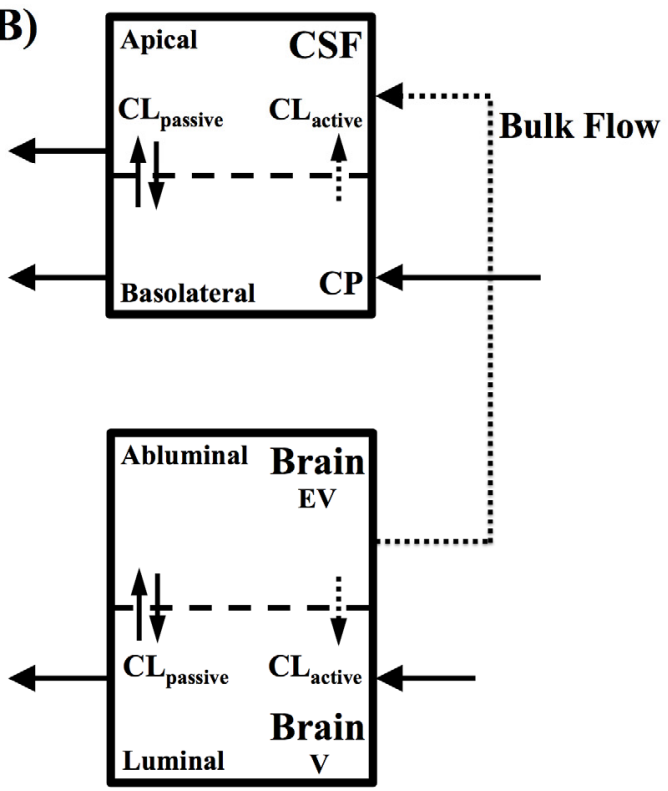

Mouse and rat tissue volumes and perfusion rates were sourced from literature sources [58] (Table 1) with drug tissue partition coefficients calculated from the tissue-composition-based approach [59,60] using $\log P$ and $\mathrm{pKa}$ parameters predicted using ChemAxon (http://www.chemaxon.com) or obtained from the literature (see Supplementary Information). Where absent in the literature, blood flow was scaled based on an allometric function (weight ${ }^{3 / 4}$ ), and tissue volumes scaled to body weight [61,62], assuming a mouse body weight of $30 \mathrm{~g}$ and rat body weight of $250 \mathrm{~g}$ [58] (see Supplementary Information). 
Table 1. Physiologically based pharmacokinetic (PBPK) model parameters for rats and mice.

\begin{tabular}{|c|c|c|c|c|}
\hline \multirow[b]{2}{*}{ Tissue } & \multicolumn{2}{|c|}{ Rat $^{a}$} & \multicolumn{2}{|c|}{ Mice $^{b}$} \\
\hline & $\begin{array}{c}\text { Blood flow } \\
(\mathrm{mL} / \mathrm{h})\end{array}$ & $\begin{array}{c}\text { Tissue volume } \\
(\mathrm{mL})\end{array}$ & $\begin{array}{c}\text { Blood flow } \\
(\mathrm{mL} / \mathrm{h})\end{array}$ & $\begin{array}{c}\text { Tissue volume } \\
(\mathrm{mL})\end{array}$ \\
\hline Arterial blood & 2580 & 5.6 & 839.0 & 0.40 \\
\hline Venous blood & 2580 & 11.3 & 839.0 & 0.81 \\
\hline Lung & 2580 & 1.6 & 839.0 & 0.12 \\
\hline Liver (Total) & 120 & 10.3 & 16.8 & 0.74 \\
\hline Hepatic artery ${ }^{c}$ & 0.29 & - & 0.28 & - \\
\hline Portal vein ${ }^{\mathrm{d}}$ & 2.12 & - & 1.96 & - \\
\hline Kidney & 553 & 2.3 & 91.9 & 0.17 \\
\hline Stomach & 8 & 1.1 & 4.8 & 0.08 \\
\hline Spleen & 37.8 & 0.6 & 9.5 & 0.04 \\
\hline Pancreas & 30 & 1.3 & 2.2 & 0.09 \\
\hline Intestine & 451 & 11 & 117.0 & 0.79 \\
\hline Muscle & 450 & 122 & 133.0 & 8.79 \\
\hline Adipose & 24 & 10 & 59.0 & 0.72 \\
\hline Skin & 350 & 40 & 48.4 & 2.88 \\
\hline Bone & 75.9 & 15.8 & 92.3 & 1.14 \\
\hline Heart & 236 & 0.8 & 55.1 & 0.06 \\
\hline Thymus & 18 & 0.7 & 1.4 & 0.05 \\
\hline Brain $^{e}$ & $120^{f}$ & 1.8 & $25.9^{\mathrm{g}}$ & 0.36 \\
\hline Brain IVS ${ }^{\mathrm{h}}$ & - & 0.025 & - & 0.005 \\
\hline Brain ISF & - & 0.33 & - & 0.067 \\
\hline ISF bulk flow & $0.03^{\mathrm{i}}$ & - & 0.0016 & - \\
\hline $\mathrm{CP}^{\mathrm{j}}$ & - & 0.0036 & - & 0.00072 \\
\hline CSF & 80 & 1.2 & 25.8 & 0.09 \\
\hline
\end{tabular}

${ }^{a}$ Taken from Brown et al. [58]; ${ }^{b}$ taken from Brown et al. [58] or blood flow scaled to the 0.75 of body weight and tissue volumes scaled to body weight (bold) [61,62]; ${ }^{\mathrm{c}}$ assuming hepatic artery flow is $2 \%$ (mouse) and 2.1\% (rat) of cardiac output [58]; ${ }^{\mathrm{d}}$ assuming portal vein flow is $14.1 \%$ (mouse) and $15.3 \%$ (rat) of cardiac output [58]; ${ }^{\text {e }}$ fractional volume of brain intravascular fluid, 0.014; Fractional volume of brain interstitial space, 0.188 [63], assuming brain weight of $1.8 \mathrm{~g}$ in rats and $0.36 \mathrm{~g}$ in mice [64]; ${ }^{\mathrm{f}}$ average of values reported from Eyal et al. [65] and Stange et al. [66]; ${ }^{\mathrm{g}}$ taken from Jay et al. [67]; ${ }^{\text {h }}$ Brain IVS: brain intravascular space; ${ }^{\mathrm{i}}$ taken from Abbott et al. [68]; and ${ }^{\mathrm{j}}$ assuming choroid plexus (CP) weight is $0.2 \%$ of brain weight [69].

The CNS was comprised of brain IVS (intravascular space), brain ISF and CSF compartments. A rate-limited permeability barrier between the IVS and ISF and IVS and CSF represented the BBB and BCSFB respectively, and was incorporated into the model as passive bi-directional clearance terms $\left(\mathrm{CL}_{\text {passive }}\right)$ and active efflux terms $\left(\mathrm{CL}_{\text {active }}\right)$ modeling both passive and active flux of compounds across each permeability barrier (Figure 1). Bulk flow of ISF was incorporated within the model to represent the flow of unbound brain ISF drug to CSF. Unbound drug fractions in plasma $\left(f u_{\mathrm{p}}\right)$, brain ISF $\left(f u_{b}\right)$ and cerebrospinal fluid $\left(f u_{C S F}\right)$ were incorporated into the plasma, brain and CSF compartments respectively. 
Well-stirred organs were described by the following equation:

$$
\frac{\mathrm{d} C_{\mathrm{t}}}{\mathrm{dt}}=\frac{Q_{\mathrm{t}}}{V_{\mathrm{t}}} \times C_{\mathrm{art}^{-}}-\frac{Q_{\mathrm{t}}}{K \mathrm{p}_{\mathrm{t}} \times V_{\mathrm{t}}} \times C_{\mathrm{t}}
$$

where $C$ is the concentration of drug, $Q_{\mathrm{t}}$ is the tissue perfusion rate, $C_{\text {art }}$ is the arterial drug input, $V_{\mathrm{t}}$ is the volume of tissue compartment and $K \mathrm{p}_{\mathrm{t}}$ is the partition coefficient of the tissue compartment.

The removal of drugs from the eliminating organs (liver and kidney) was described by additional clearance terms (hepatic clearance: $\mathrm{CL}_{\mathrm{H}}$ and renal clearance: $\mathrm{CL}_{\mathrm{R}}$ ). Hepatic clearance was predicted from in vivo data (human blood or plasma clearance: $\mathrm{CL}_{\mathrm{b}}$ or $\mathrm{CL}_{\mathrm{p}}$ or in vitro data (in vitro intrinsic metabolic clearance: $\mathrm{CL}_{\text {int, in vitro }}$ ) and renal clearance was calculated using a GFR (glomerular filtration rate) correction approach [70].

When using $\mathrm{CL}_{\mathrm{b}}$ or $\mathrm{CL}_{\mathrm{p}}$ as an input, the in vivo intrinsic clearance $\left(\mathrm{CL}_{\text {int, in vivo }}\right)$ was calculated (Equation (6)) by, if necessary, correcting for the blood:plasma ratio $\left(R_{\mathrm{b}}\right)$ (Equation (7)) (or, where not available, by assuming $R_{\mathrm{b}}=1$ for basic drugs and $R_{\mathrm{b}}=0.55$ for neutral and acidic drugs), and scaled using an allometric function of body weight (weight ${ }^{3 / 4}$ ) to yield a species-specific $\mathrm{CL}_{\text {int, in vivo }}$.

$$
\begin{gathered}
\mathrm{CL}_{\text {int, in vivo }}=\frac{\mathrm{CL}_{\mathrm{b}}}{f \mathrm{u}_{\mathrm{b}} \times\left(1-\frac{\mathrm{CL}_{\mathrm{b}}}{Q_{\mathrm{H}}}\right)} \\
f \mathrm{u}_{\mathrm{b}}=\frac{f \mathrm{u}_{\mathrm{p}}}{R_{\mathrm{b}}}
\end{gathered}
$$

When using the in vitro intrinsic metabolic clearance $\left(\mathrm{CL}_{\mathrm{int}}\right.$, in vitro $)$ as input, an in vivo intrinsic

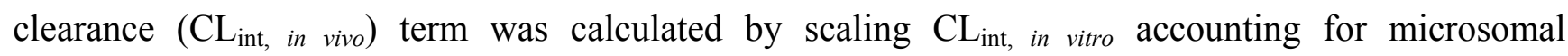
recovery (microsomal protein content (rat: 45 milligrams protein per gram of liver [71] or hepatocellularity $130 \times 10^{6}$ cells per gram of liver) [72,73] and rat or mouse liver weight (40 grams per kilogram body weight [58] and 88 grams per kilogram body weight [71] respectively.

The unbound hepatic plasma clearance was then calculated using a well-stirred liver model (Equation (8)), where hepatic blood flow $\left(Q_{\mathrm{h}}\right)$ was assumed to be $55 \mathrm{~mL} \mathrm{~min}^{-1} \mathrm{~kg}^{-1}$ (rats) and $90 \mathrm{~mL} \mathrm{~min}^{-1} \mathrm{~kg}^{-1}$ (mice) [71].

$$
\mathrm{CL}_{\mathrm{H}}=\frac{f \mathrm{u}_{\mathrm{p}} \times \mathrm{CL}_{\mathrm{int}, \text { in vivo }} \times Q_{\mathrm{h}}}{Q_{\mathrm{h}}+f \mathrm{u}_{\mathrm{p}} \times \mathrm{CL}_{\mathrm{int}, \text { in vivo }} / R_{\mathrm{b}}}
$$

For compounds which are cleared renally, unbound renal clearance $\left(\mathrm{CL}_{\mathrm{R}}\right)$ was predicted using the GFR approach described by Lin [71] and by assuming a rat/human GFR ratio of 4.8 and a mouse/human GFR ratio of 6.6 (Mouse GFR $=12 \mathrm{~mL} / \mathrm{min} / \mathrm{kg}$ [74]), corrected for rat $f \mathrm{u}_{\text {plasma. }}$.

Permeability rate-limited transport across the BBB was described by Equations (9) and (10).

Vascular compartment:

$$
\frac{\mathrm{d} C_{\mathrm{v}}}{\mathrm{dt}}=\frac{Q_{\mathrm{t}}}{V_{v}} \times C_{\mathrm{art}}-\frac{Q_{\mathrm{t}}}{V_{v}} \times C_{\mathrm{v}}-\frac{C \mathrm{~L}_{\text {passive }, \mathrm{LA}}}{V_{v}} \times f \mathrm{u}_{\mathrm{p}} \times C_{\mathrm{v}}+\frac{C \mathrm{~L}_{\text {passive, } \mathrm{AL}}}{V_{v}} \times f \mathrm{u}_{\mathrm{b}} \times C_{\mathrm{ev}}+\frac{\mathrm{CL}_{\text {active }}}{V_{v}} \times f \mathrm{u}_{\mathrm{b}} \times C_{\mathrm{ev}}
$$

Extra-vascular compartment:

$$
\frac{\mathrm{d} C_{\mathrm{ev}}}{\mathrm{dt}}=\frac{C \mathrm{~L}_{\mathrm{passive}, \mathrm{LA}}}{V_{\mathrm{ev}}} \times f \mathrm{u}_{\mathrm{p}} \times C_{\mathrm{v}}-\frac{C \mathrm{CL}_{\mathrm{passive}, \mathrm{AL}}}{V_{\mathrm{ev}}} \times f \mathrm{u}_{\mathrm{b}} \times C_{\mathrm{ev}}-\frac{C \mathrm{C}_{\mathrm{active}}}{V_{\mathrm{ev}}} \times f \mathrm{u}_{\mathrm{b}} \times C_{\mathrm{ev}}-\frac{Q_{\mathrm{bf}}}{V_{\mathrm{ev}}} \times f \mathrm{u}_{\mathrm{b}} \times C_{\mathrm{ev}}
$$


where $Q_{\mathrm{t}}$ is tissue perfusion rate, $V_{\mathrm{ev}}$ is extra-vascular volume, $V_{\mathrm{v}}$ is the vascular volume, $\mathrm{CL}_{\text {passive }}$ is the passive clearance across the BBB (subscript denotes either luminal-to-abluminal or abluminal-to-luminal flux), $f \mathrm{u}_{\mathrm{p}}$ is free drug fraction in plasma and $f \mathrm{u}_{\mathrm{b}}$ is free drug fraction in brain.

Permeability rate-limited transport across the BCSFB was described by Equations (11) and (12).

CP compartment:

$$
\frac{\mathrm{d} C_{\mathrm{cp}}}{\mathrm{dt}}=\frac{Q_{\mathrm{t}}}{V_{\mathrm{cp}}} \times C_{\mathrm{art}}-\frac{Q_{\mathrm{t}}}{V_{\mathrm{cp}}} \times C_{\mathrm{cp}}-\frac{\mathrm{CL}_{\mathrm{passive}, \mathrm{BA}}}{V_{\mathrm{cp}}} \times f \mathrm{u}_{\mathrm{p}} \times C_{\mathrm{cp}}+\frac{C \mathrm{~L}_{\mathrm{passive}, \mathrm{AB}}}{V_{\mathrm{cp}}} \times f \mathrm{u}_{\mathrm{CSF}} \times C_{\mathrm{CSF}}-\frac{\mathrm{CL}_{\mathrm{active}}}{V_{\mathrm{cp}}} \times f \mathrm{u}_{\mathrm{p}} \times C_{\mathrm{cp}}
$$

CSF compartment:

$$
\frac{\mathrm{d} C_{\mathrm{CSF}}}{\mathrm{dt}}=\frac{Q_{\mathrm{bf}}}{V_{\mathrm{CSF}}} \times f \mathrm{u}_{\mathrm{brain}} \times C_{\mathrm{ev}}-\frac{Q_{\mathrm{t}}}{V_{\mathrm{CSF}}} \times C_{\mathrm{CSF}}+\frac{\mathrm{CL}_{\mathrm{passive}, \mathrm{BA}}}{V_{\mathrm{CSF}}} \times f \mathrm{u}_{\mathrm{p}} \times C_{\mathrm{cp}}-\frac{\mathrm{CL}_{\mathrm{passive}, \mathrm{AB}}}{V_{\mathrm{CSF}}} \times f \mathrm{u}_{\mathrm{CSF}} \times C_{\mathrm{CSF}}+\frac{\mathrm{CL}_{\text {active }}}{V_{\mathrm{CSF}}} \times f \mathrm{u}_{\mathrm{p}} \times C_{\mathrm{cp}}
$$

where $Q_{\mathrm{t}}$ is the perfusion rate, $V_{\mathrm{cp}}$ is choroid plexus cellular volume, $V_{\mathrm{CSF}}$ is the CSF volume, $\mathrm{CL}_{\text {passive }}$ is the passive clearance across the BCSFB (subscript denotes either basolaterial-to-apical (BA) or apical-to-basolaterial (AB) flux), $f u_{b}$ is free drug fraction in brain, $f u_{p}$ is free drug fraction in plasma, $f \mathrm{u}_{\mathrm{CSF}}$ is free drug fraction in CSF and $C_{\mathrm{ev}}$ is the concentration in the brain extravascular compartment.

\subsubsection{Extrapolation of Passive Transport}

Where apparent permeability $\left(P_{\text {app }}\right)$ was reported in the absence and presence of transporter inhibitor, passive transport was assumed to be represented by the extent of inhibition. Where apparent permeability was reported in wild type and knock-out animals, passive transport was assumed to be the difference in apparent permeability. Passive bi-directional transport across the brain capillary was assumed to be represented by the apical-to-basolateral flux $\left(P_{\mathrm{app}, \mathrm{AB}}\right)$ and basolateral-to-apical flux $\left(P_{\text {app,BA }}\right)$ in the non-transfected LLC-PK1 cell line (by correcting for the insert surface area $\left(0.33 \mathrm{~cm}^{2}\right)$ and expressed as $\mathrm{cm} / \mathrm{h}$ ), and extrapolated to in vivo $\mathrm{CL}_{\text {passive }}$ for the luminal-to-abluminal (blood-to-brain) and abluminal-to-luminal (brain-to-blood) directions. Passive transport was effectively extrapolated to an in vivo passive clearance term based on correction for in vivo brain vascular endothelial surface area (SA), $150 \mathrm{~cm}^{2} \mathrm{~g} \mathrm{brain}^{-1}$ for rats [75] and $240 \mathrm{~cm}^{2} \mathrm{~g} \mathrm{brain}^{-1}$ for mice [44] and brain weight (rat: $0.57 \%$ of body weight; mouse: $1.6 \%$ of body weight [58]) yielding $\mathrm{CL}_{\text {passive,LA }}$

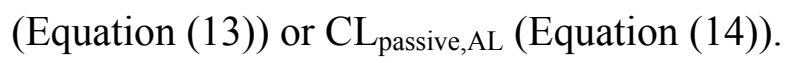

$$
\begin{aligned}
& \mathrm{CL}_{\text {passive } \mathrm{LA}}=\operatorname{Papp}_{\mathrm{AB}} \times \mathrm{SA} \times \text { Brain weight } \\
& \mathrm{CL}_{\text {passive, } \mathrm{AL}}=P \operatorname{Papp}_{\mathrm{BA}} \times \mathrm{SA} \times \text { Brain weight }
\end{aligned}
$$

No studies have directly correlated drug permeability, in vitro or in vivo, at the BCSFB and the BBB. However, the in vivo permeability-surface area product (PS) of quinolone antibiotics at the choroid plexus [76,77] has been modeled in rats, and whilst based on pharmacokinetic modeling approaches, yielded similar in vivo permeabilities at the $\mathrm{BBB}\left(\mathrm{PS}_{\mathrm{BBB}}\right)$ and $\mathrm{BCSFB}\left(\mathrm{PS}_{\mathrm{CSF}}\right)$, when corrected for tissue weight. Furthermore the paracellular permeability of sucrose in monolayers of primary rat brain endothelial cells (average of 5 studies: $2-11 \times 10^{-6} \mathrm{~cm} / \mathrm{s}$ [78-82], is similar to that reported in monolayers of primary rat choroid plexus cells $\left(7 \times 10^{-6} \mathrm{~cm} / \mathrm{s}[83]\right)$.

Due to the absence of either in vitro or in vivo choroidal epithelial permeability data for many compounds, passive flux across the BCSFB was extrapolated based on correcting for in vivo choroid 
plexus surface area $\left(75 \mathrm{~cm}^{2}\right.$ in rats [27]) to yield an in vivo permeability clearance at the BCSFB $\left(\mathrm{CL}_{\text {passive, BCSFB }}\right)$ (Equation (15)):

$$
\mathrm{CL}_{\text {passive }}=P_{\mathrm{app}} \times \mathrm{SA}
$$

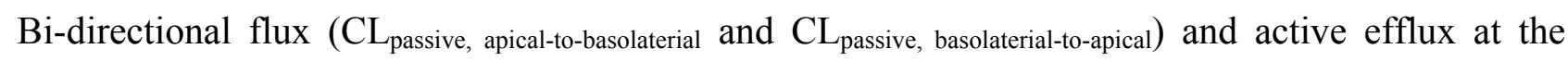
$\mathrm{BCSFB}$ was parameterised using a similar approach to that detailed for the BBB.

When using in vivo reported $\mathrm{CL}_{\text {passive }}$ to describe passive permeability at the $\mathrm{BBB}, \mathrm{CL}_{\text {passive }}$ at the BCSFB was scaled based on the BCSFB:BBB surface area.

\subsubsection{Extrapolation of Active Transport}

Effective extrapolation of in vitro determined active transport data requires knowledge of cellular transporter expression within the in vitro system and within the target tissue to account for variations in transporter expression. To address this, Ball et al. [43] reported an approach that utilised either a relative activity factor (RAF) or a physiological scaling factor to relate activity/expression of transporters within in vitro systems to an in vivo metric. Furthermore, Hoffmeyer et al. [84] suggested that the transport activity of P-glycoprotein in human is dependent on the level of protein expression. Similarly, Shirasaka et al. [85] and Tachibana et al. [86] also demonstrated that P-glycoprotein transport activity in vivo was proportional to its protein expression levels in vitro. Given these findings we have assumed $m d r l a$ activity is directly related to $m d r l a$ protein expression level and the in vitro intrinsic transport activity of $m d r l a$ (transport rate per $m d r l a$ protein) is identical to that in vivo in rats. The availability of P-glycoprotein and BCRP efflux kinetics terms is limited for a vast number of compounds in the literature and hinders widespread utilisation of PBPK modeling to assess the brain distribution of drugs. In lieu of widespread and robust Michaelis-Menten kinetics parameters for transporter substrates, the active efflux component of drug transport was described by a corrected efflux ratio (ER) [55,87] (Equation (16)) derived from the ratio of the efflux ratio in $m d r 1$ - or $B C R P$-transfected cells and vector-transfected control cells.

$$
E R_{\text {corrected }}=\frac{E R_{\text {functional }}}{E R_{\text {non-functional }}}
$$

To correct for the difference in protein abundance between in vitro cell lines and brain capillaries, an abundance-scaling factor (ASF) was incorporated to represent the ratio of in vivo-to-in vitro capillary abundance of transporter protein in cell lines (see Section 2.1.5) and either mice (P-glycoprotein; $14.1 \mathrm{fmol} / \mu \mathrm{g}$ protein or BCRP; $4.41 \mathrm{fmol} / \mu \mathrm{g}$ protein [56]) or rats (P-glycoprotein; $19.1 \mathrm{fmol} / \mu \mathrm{g}$ protein or BCRP; $4.95 \mathrm{fmol} / \mu \mathrm{g}$ protein [57]). For BCRP, in vitro abundance data were not available in the MDCK-II-BCRP cell line and therefore ASF was set as equal to 1. Subsequently active clearance was incorporated into the model as the product of the corrected in vivo efflux ratio and luminal-to-abluminal passive clearance (Equation (17)).

$$
\mathrm{CL}_{\text {active }}=E R_{\text {corrected }} \times \mathrm{CL}_{\text {passive }, \mathrm{LA}} \times \mathrm{ASF}
$$

Active efflux at the BCSFB was modelled using a similar approach, with directionality of efflux transport being from the systemic circulation into the CSF. The proposed model incorporates active efflux for two widely investigated drug efflux transporters, P-glycoprotein and BCRP. Alternative 
transporter proteins with similar transport directionality could be paramatised within the model using in vitro passive and active permeability data for a specific transporter protein along with the protein abundance of the transporter(s).

\subsubsection{Model Validation: Prediction of Temporal Brain and Plasma Concentrations in Rats}

To validate the PBPK model the plasma and brain concentrations of the antibiotic norfloxacin were modeled and compared to in vivo measurements in rats. Norfloxacin plasma pharmacokinetics in rats, following an intravenous (IV) bolus of $150 \mathrm{mg} \mathrm{kg}^{-1}$, has been described by a 2-compartment model [88]. For modeling purposes, the unbound fraction of norfloxacin in brain was assumed to be equal to 1. This approach can be rationalised since the unbound brain volume of distribution ( $V_{\mathrm{u} \text {,brain }}$ [89] for norfloxacin $\left(0.98 \pm 0.59 \mathrm{~mL} \mathrm{~g}\right.$ brain $\left.^{-1}\right)$, is similar to the brain water volume $\left(0.8 \mathrm{~mL} \mathrm{~g}\right.$ brain $\left.^{-1}\right)$ [90] suggesting limited brain binding. Predicted norfloxacin brain ISF- and plasma concentration-time profiles were compared with in vivo norfloxacin brain ISF (determined using microdialysis) and plasma concentration-time profiles from 10 rats (pharmacokinetic data provided by Chenel et al. [88]).

\subsubsection{Prediction of $K \mathrm{p}_{u u, b r a i n}$ and $\mathrm{CSF}_{\mathrm{u}}: \mathrm{Plasma}_{\mathrm{u}}$ in Rat}

The rat $\mathrm{CNS}$ hybrid PBPK model was used to predict $K \mathrm{p}_{\mathrm{uu}}$,brain and $\mathrm{CSF}_{\mathrm{u}}$ :Plasma $\mathrm{u}_{\mathrm{u}}$. Permeation across the $\mathrm{BBB}$ and $\mathrm{BCSFB}$ was incorporated into the model using in vitro permeability determined in the L-mdrla cell line, as reported by Uchida et al. [55] and detailed in Section 2.1.3. All compounds were simulated as intravenous bolus doses. $K \mathrm{p}_{u u, b r a i n}$ and $\mathrm{CSF}_{\mathrm{u}}: \mathrm{Plasma}_{\mathrm{u}}$ were predicted for a dataset of

25 compounds where in vitro permeability, $f \mathrm{u}_{\text {plasma, }} f \mathrm{u}_{\text {brain, }} f \mathrm{u}_{\mathrm{CSF}}, K \mathrm{p}_{\mathrm{uu} \text {,brain }}$ and $\mathrm{CSF}_{\mathrm{u}}: \mathrm{Plasma}_{\mathrm{u}}$ had previously been reported in rats [53] (see Supplementary Information).

\subsection{Prediction of $K p_{u u, b r a i n}$ for Actively Effluxed Compounds in Mice}

In order to assess the utility of in vitro-derived cell culture permeability data to predict CNS drug disposition for actively effluxed compounds in mice, a whole body CNS PBPK model was parameterised with physiological tissue volumes and perfusion rates obtained from literature [91], with any absent data assumed to be equivalent to rats $[59,60]$. Permeation across the BBB and BCSFB was incorporated into the model using in vitro permeability determined in the L-mdrla cell line, as reported by Uchida et al. [55] and the brain disposition of 11 P-glycoprotein substrates was modeled and predictions compared to reported $K \mathrm{p}_{\text {uu,brain }}$ in mice [55]. All compounds were simulated as intravenous bolus doses.

\subsection{Sensitivity Analysis}

To further explore the factors that influence the disposition of drugs into the brain biophase, a series of additional simulations were conducted exploring the impact of variation in $\mathrm{CL}_{\text {passive }}$ (luminal-to-abluminal and abluminal-to-luminal were assumed equal), $E R, f \mathrm{u}_{\text {plasma }}$ and $f \mathrm{u}_{\text {brain }}$ on $K \mathrm{p}_{\mathrm{uu}, \text { brain }}$ and $\mathrm{CSF}_{\mathrm{u}}: \mathrm{Plasma}_{\mathrm{u}}$ utilising input parameters based on a model compound selected from the $K \mathrm{p}_{\mathrm{uu}, \text { brain }}$ and $\mathrm{CSF}_{\mathrm{u}}: \mathrm{Plasma}_{\mathrm{u}}$ predictions. 


\subsection{Assessment of Prediction Accuracy}

The predictability of individual compounds was assessed using a fold-error $(F E)$ approach where: Predicted > Observed:

$$
F E=\frac{\text { predicted }}{\text { observed }}
$$

Observed > Predicted:

$$
F E=\frac{\text { observed }}{\text { predicted }}
$$

Prediction accuracy was assessed by the average fold error (afe) approach (geometric mean error) (Equation (20)):

$$
\text { afe }=10^{\left[\frac{1}{n} \sum \log \frac{\text { predicted }}{\text { observed }}\right]}
$$

Precision of prediction was assessed using root mean squared error (rmse) (Equation (21)) where $n$ refers to the number of observations.

$$
\text { rmse }=\sqrt{\frac{1}{n} \sum(\text { prediction }- \text { observed })^{2}}
$$

The percentage of compounds within a 3-fold, 4-fold, 5-fold and $>5$-fold error was derived from predicted and observed values.

\section{Results and Discussion}

The availability of in vivo permeability measurements for candidate compounds undergoing pre-clinical assessment often remains a limiting factor for efficient and effective use of pharmacokinetic models attempting to model CNS drug disposition. Consequently, in vitro permeability data for passively and actively transported compounds are often used to extrapolate to in vivo permeability. Polli et al. [92] demonstrated a linear relationship between brain penetration (Kin) in rat in situ brain perfusion studies and apparent permeability in MDCK type-1 cells with a correlation coefficient of 0.86 . A similar trend was reported between brain uptake index (BUI) and permeability across bovine brain endothelial cell cultures, with a correlation coefficient of 0.89 [50]. In more recent studies Uchida et al. [54] and Kodaira et al. [53] have demonstrated the utility of murine-mdr1a-expressing LLC-PK1 cells (L-mdr1a) to reconstruct $K \mathrm{p}_{\mathrm{uu}}$,brain and $\mathrm{CSF}_{\mathrm{u}}:$ Plasma $\mathrm{u}_{\mathrm{u}}$ for a handful of P-glycoprotein substrates.

Our primary goal was to build upon existing approaches aimed at mechanistically predicting CNS drug disposition and examine the potential application of drug permeability data derived from L-mdr1a cells to predict $K \mathrm{p}_{\mathrm{uu} \text {,brain }}$ in mice and both $K \mathrm{p}_{\mathrm{uu} \text {,brain }}$ and $\mathrm{CSF}_{\mathrm{u}}: \mathrm{Plasma}_{\mathrm{u}}$ in rats. Development of a PBPK model capable of predicting CNS drug disposition by extrapolation of in vitro-derived data may prove a valuable resource for rapid pre-clinical screening of candidate compounds during development. 


\subsection{Validation of the PBPK Model}

To validate the PBPK model structure and the ability to predict both plasma and brain ISF temporal concentrations, we selected norfloxacin as a model compound and utilised published rat norfloxacin plasma data and brain pharmacokinetic data obtained by microdialysis [88].

Norfloxacin plasma (Figure 2) and brain (Figure 3) temporal concentration profiles were both predicted to be within the ranges observed in vivo. Simulation of brain ISF norfloxacin concentration-time profile using literature derived $\mathrm{CL}_{\text {passive }}$ (value obtained from fitting to in vivo data) [76,77] in the absence of a P-glycoprotein/BCRP-type active efflux component yielded predictions in which the absorption and elimination phases were outside the range observed in vivo (Figure 3). Subsequent simulations using a $\mathrm{CL}_{\text {passive }}$ 2-fold higher than the initial fitted value (Table 2) and P-glycoprotein/BCRP-type active efflux processes (efflux ratio of 3) resulted in absorption and elimination phases within the range reported in 10 rats by Chenel et al. [88] (Figure 3).

Importantly, incorporation of an active efflux component (P-glycoprotein/BCRP type) within our simulations corrected the over-prediction in brain ISF drug concentrations and demonstrated the importance of an efflux clearance mechanism in governing norfloxacin CNS drug disposition. These findings are consistent with those of Chenel et al. [88] who demonstrated the influence of efflux clearance mechanisms on norfloxacin brain pharmacokinetics. The inclusion of a P-glycoprotein/BCRP type active efflux component within our norfloxacin simulations is supported by a recent report demonstrating norfloxacin to be a BCRP substrate [93].

Figure 2. Model predicted norfloxacin plasma concentrations in rats. Small closed circles represent literature reported plasma concentrations determined in rats following an IV-bolus dose [88]. Large closed circles represent model predicted norfloxacin plasma concentrations in rats in the absence of efflux. Large open circles represent model predicted norfloxacin plasma concentrations in rats in the presence of efflux (efflux ratio $=3$ ).

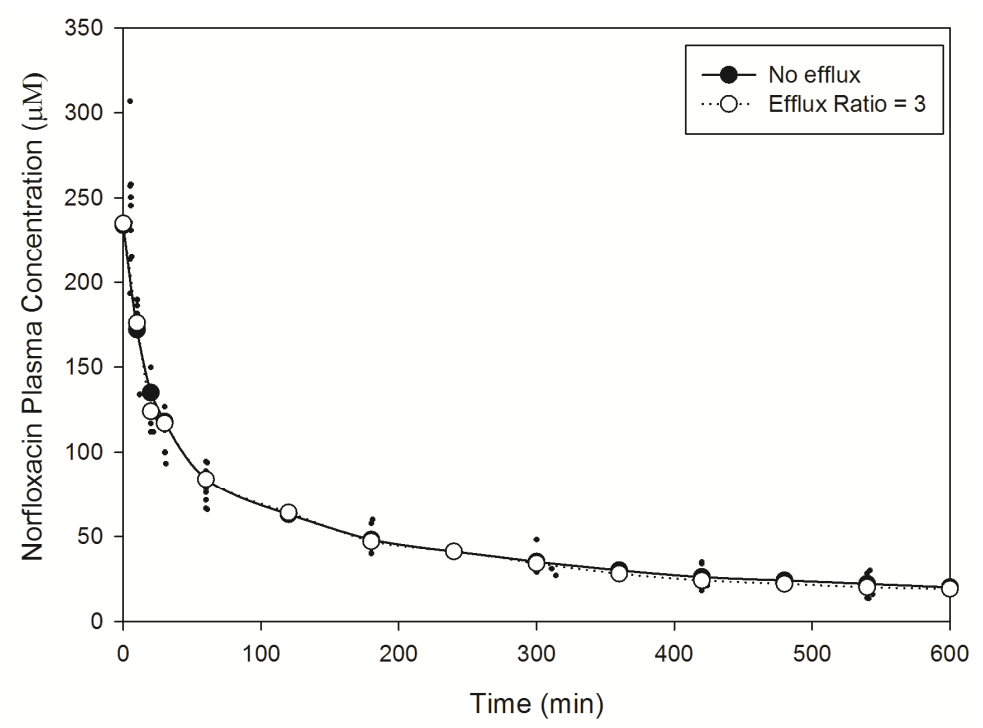


Figure 3. Model predicted norfloxacin brain concentrations in rats. Crosses represent literature reported brain concentration determined in rats following an IV-bolus dose [88]. Closed circles represent model predicted norfloxacin brain concentrations in rats in the absence of efflux. Open circles represent model predicted norfloxacin brain concentrations in rats in the presence of efflux (efflux ratio $=3$ ).

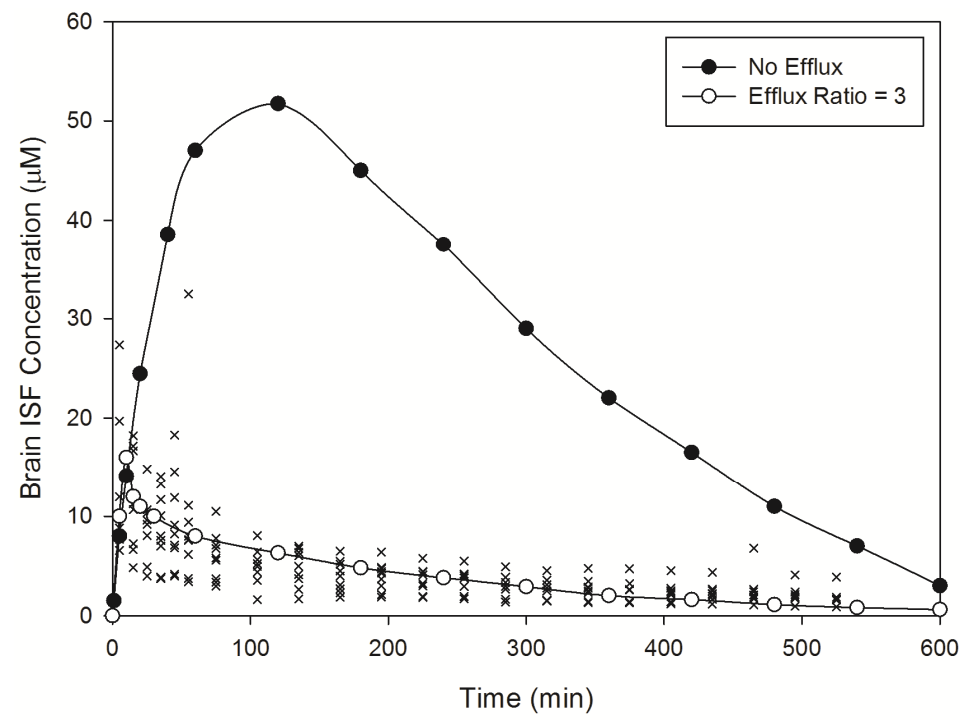

Norfloxacin $K p_{\text {brain }}$ was predicted to be 0.141 , within 2 -fold of the observed $K p_{\text {brain }}$ of 0.091 , whilst norfloxacin CSF:plasma was predicted to be 0.089, within 2.1-fold of the observed CSF:plasma of 0.043 (Table 2). Predicted plasma half-life was extremely close to observed half-life whilst brain ISF half-life was within 1.5-fold of the observed value (Table 2).

Table 2. Prediction of norfloxacin plasma, brain and CSF pharmacokinetics.

\begin{tabular}{lll}
\hline Parameter & Value & Unit \\
\hline Predicted $K \mathrm{p}_{\text {brain }}$ & 0.141 & \\
Mean observed $K \mathrm{p}_{\text {brain }}$ & $0.093^{\mathrm{a}}$ & \\
Predicted CSF:Plasma & 0.089 & \\
Observed CSF:Plasma & $0.043^{\mathrm{b}}$ & \\
Predicted $t_{1 / 2, \text { plasma }}(E R=3)$ & 183 & $\left(\min ^{-1}\right)$ \\
Observed $t_{1 / 2, \text { plasma }}{ }^{-1}$ & $202 \pm 45$ & $\left(\min ^{-1}\right)$ \\
Predicted $t_{1 / 2, \text { ISF }}(E R=3)$ & 231 & $\left(\min ^{-1}\right)$ \\
Observed $t_{1 / 2, \text { ISF }}$ & $255 \pm 97$ & $\left(\min ^{-1}\right)$ \\
Predicted $A U C_{\text {plasma }}$ & 340 & $\left(\mu \mathrm{Mmin}^{-1}\right)$ \\
Predicted $A U C_{\mathrm{ISF}}(\mathrm{ER}=0)$ & 329 & $\left.(\mu \mathrm{M} \mathrm{min})^{-1}\right)$ \\
Predicted $A U C_{\mathrm{ISF}}(\mathrm{ER}=3)$ & 47.9 & $\left.(\mu \mathrm{M} \mathrm{min})^{-1}\right)$ \\
Predicted $A U C_{\mathrm{CSF}}(\mathrm{ER}=3)$ & 30.4 & $\left.(\mu \mathrm{M} \mathrm{min})^{-1}\right)$ \\
Predicted ISF $C_{\max }(\mathrm{ER}=0)$ & 52.4 & $(\mu \mathrm{M})$ \\
Predicted ISF $C_{\max }(\mathrm{ER}=3)$ & 16.3 & $(\mu \mathrm{M})$ \\
\hline
\end{tabular}

${ }^{\mathrm{a}}$ Mean of three reported values $\left(K \mathrm{p}_{\text {u,brain }}: 0.035 \pm 0.014\right.$ and $K \mathrm{p}_{\text {brain: }} 0.044$ [77], $K \mathrm{p}_{\text {brain: }} 0.097 \pm 0.029$ [76] and 0.067 [89]); ${ }^{b}$ Mean of two reported values (CSF:P $\mathrm{P}_{\mathrm{u}}, 0.033 \pm 0.006$ and CSF:P, 0.042 [77], CSF:P $\mathrm{P}_{\mathrm{u}}, 0.044 \pm 0.010$ and CSF:P, 0.056 [94]); ${ }^{\mathrm{c}}$ Reported parameter estimate from compartmental analysis [88]; and ${ }^{\mathrm{d}}$ Reported parameter estimate from non-compartmental analysis [95]. 


\subsection{Prediction of Central Nervous System (CNS) Disposition Using L-mdrla in Vitro Permeability Data}

Recent studies report positive correlations between drug permeability assessed in the LLC-PK1 porcine kidney cell line transfected with murine $m d r l$ (to produce the L-mdrla cell line) and in vivo brain distribution of P-glycoprotein substrates in rats and mice [53].

Furthermore, due to the similarity in the abundance of P-glycoprotein in L-mdr1a cells (15.2 fmol/ $\mu \mathrm{g}$ protein) compared to the abundance in brain capillaries (Mouse: $14.1 \mathrm{fmol} / \mu \mathrm{g}$ protein [56]; rat: $19.1 \mathrm{fmol} / \mu \mathrm{g}$ protein [57]), we examined the use of L-mdrla-derived in vitro permeability data in predicting CNS drug disposition.

In an attempt to examine the validity of the scaling approach to determine permeability clearance at the BBB, based on extrapolating in vitro permeability data, we obtained literature reported in situ brain permeability-surface area products (PS) for 16 compounds spanning over a 100-fold range of PS.

With the exception of three compounds (midazolam, diazepam and sertraline), 11 of 13 compounds fell within 3-fold and 2 within 4-fold of the reported PS values (see Supplementary Information Section 4). Similar trends have been previously reported by Uchida et al. (2011) in LLC-PK1 cells [55], Polli et al. (2000) [92] and Summerfield et al. (2007) [96] in cultured kidney epithelial cells, and support the extrapolation approach.

\subsubsection{Prediction of $K \mathrm{p}_{\mathrm{uu}, \text { brain }}$ for 11 Actively Transported Compounds in Mice}

Using L-mdrla-derived permeability data reported by Uchida et al. [55], the predicted $K \mathrm{p}_{\text {uu,brain }}$ for over $90 \%$ of $\mathrm{P}$-glycoprotein substrates was within 4 -fold of observed $K \mathrm{p}_{u u, b r a i n}$. The predicted $K \mathrm{p}_{\mathrm{uu} \text {,brain }}$ for all compounds was within 5 -fold of observed $K \mathrm{p}_{\text {uu,brain }}$ (Figure $4 \mathrm{~A}, \mathrm{~B}$ ), with an overall afe and $r m s e$ of 0.7 and 0.23 respectively (Table 3 ).

Figure 4. Comparison of predicted and reported $K \mathrm{p}_{\mathrm{uu} \text {,brain }}$ in mice. (A) Solid bold mid-line represents the line of unity and solid outer-lines represent 4-fold prediction error; and $(\mathbf{B})$ residuals plot.

(A)

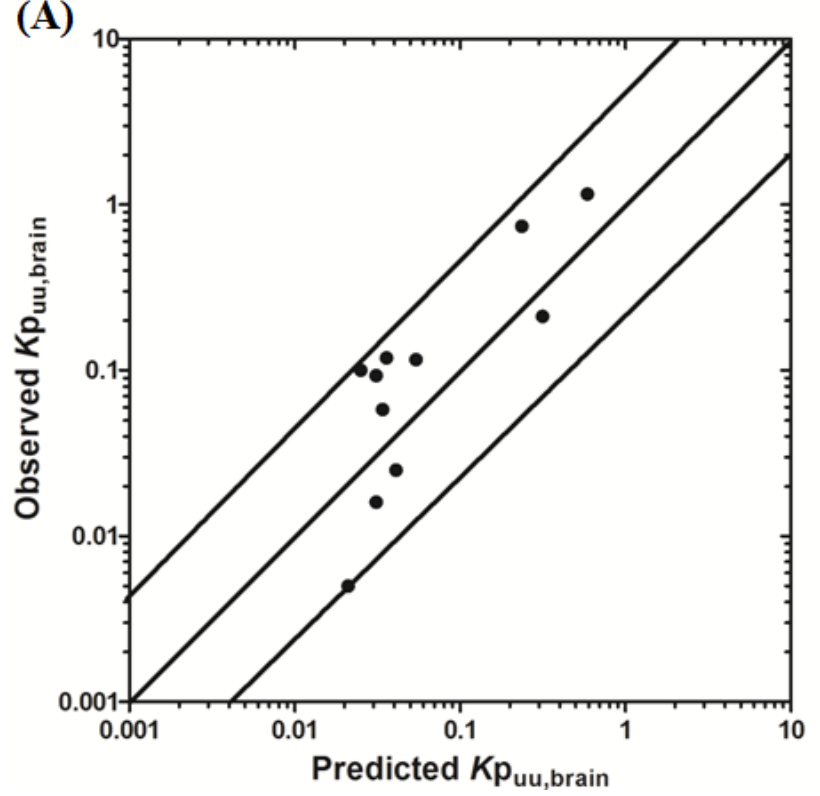

(B)

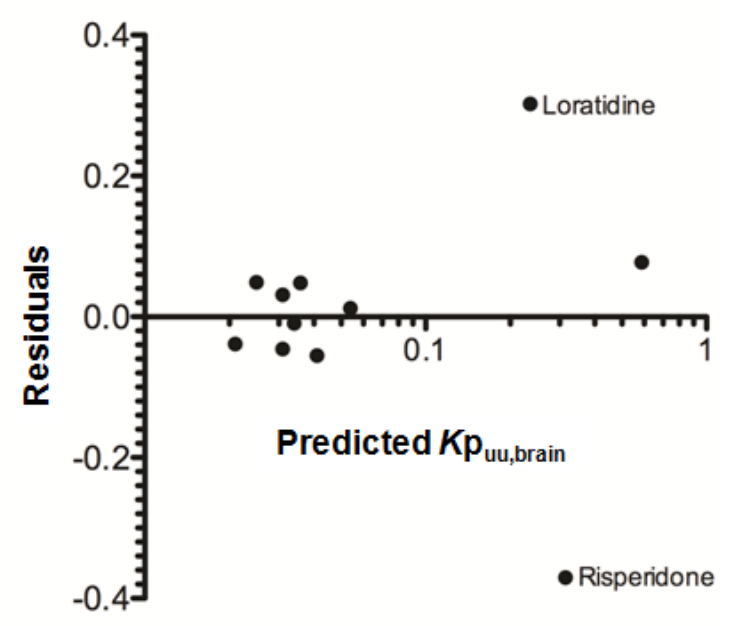


Table 3. Statistics for the model predictions.

\begin{tabular}{ccccccccc}
\hline \multirow{2}{*}{ Species } & Tissue & \multirow{2}{*}{ afe } & rmse & $\begin{array}{c}\text { \% within } \\
\text { 3-fold }\end{array}$ & $\begin{array}{c}\text { \% within } \\
\text { 4-fold }\end{array}$ & $\begin{array}{c}\text { \% within } \\
\text { 5-fold }\end{array}$ & $\begin{array}{c}\%> \\
\text { 5-fold }\end{array}$ \\
\hline \multirow{2}{*}{ Mouse } & Brain & 11 & 0.7 & 0.23 & 63.6 & 90.9 & 100 & 0 \\
\multirow{2}{*}{ Rat } & Brain & 27 & 1.19 & 0.43 & 63 & 81.5 & 88.9 & 11.1 \\
& CSF & 27 & 0.8 & 0.32 & 77.8 & 81.5 & 96.3 & 3.7 \\
\hline
\end{tabular}

Uchida et al. [55] successfully demonstrated that $K p_{\text {brain }}$ (and $K p_{u u, b r a i n}$ ) could effectively be reconstructed though the integration of in vitro mdrla transport activity and mdrla protein expression levels in the brain capillaries and in mdrla-transfected cell monolayers. Our model yielded reasonable predictions for passively transported and actively transported P-glycoprotein substrates and demonstrated the successful extrapolation of in vitro permeability data to yield an in vivo transfer clearance across the brain capillaries.

The basis of these predictions is quantitative calculation of the temporal drug concentrations in plasma and brain compartments. Whilst Uchida et al. [55] initially reconstructed $K \mathrm{p}_{\text {uu,brain, for the }}$ first time we have shown that, using a well-designed PBPK modeling approach, plasma and brain ISF temporal concentrations, and $K p_{u u, b r a i n}$ can be adequately predicted in mice for a range of P-glycoprotein substrates, using a simple set of physiochemical and pre-clinically determined parameters.

\subsubsection{Prediction of Rat $K \mathrm{p}_{\mathrm{uu}, \mathrm{brain}}$ and $\mathrm{CSF}_{\mathrm{u}}: \mathrm{Plasma}_{\mathrm{u}}$}

In an attempt to assess the utility of L-mdrla-derived permeability data to predict cross-species CNS distribution, we utilised L-mdrla permeability data from 25 compounds to predict in vivo CNS distribution $\left(\mathrm{Kp}_{\mathrm{uu} \text {,brain }}\right.$ and $\left.\mathrm{CSF}_{\mathrm{u}}: \mathrm{Plasma}_{\mathrm{u}}\right)$ in rat. Our reported model was capable of predicting rat brain disposition $\left(K \mathrm{p}_{\mathrm{uu}, \text { brain }}\right)$ for $81.5 \%$ of compounds simulated to within 4 -fold of the reported $K \mathrm{p}_{\mathrm{uu}, \text { brain }}$ (Table 3 and Figure 5). The predicted $K \mathrm{p}_{\text {uu,brain }}$ of quinidine was within 6.8 -fold of observed $K \mathrm{p}_{\text {uu,brain, }}$, whilst that of loperamide within 7.4 -fold. The overall afe and rmse were 1.19 and 0.43 respectively (Table 3).

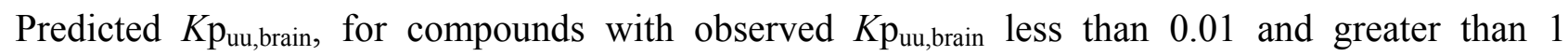
deviated further from the line of unity (Figure 5A and local regression (LOESS) plot in Supplementary Information Section 5) but were nevertheless predicted within 4-fold of the reported $K \mathrm{p}_{\mathrm{uu} \text {,brain }}$.

For flavopirodol and perfloxacin, the use of either MDCKII or LLC-PK1-derived cell permeability data did not significantly alter model predictions.

$K \mathrm{p}_{\text {brain }}$ for P-glycoprotein substrates ranges from 1 to 50 [97]. The $K \mathrm{p}_{\mathrm{uu}, \text { brain }}$ of quindine and loperamide, typical P-glycoprotein substrates, were 7.4-fold over-predicted in our model. Recent reports have identified a 39.4-fold [55] to 44-fold [53] increase in $K p_{\text {brain }}$ when comparing wild-type to knock-out mice for quinidine and 23.3-fold [55] for loperamide. For these highly effluxed compounds, the use of in vitro permeability data may not truly reflect the extent of in vivo efflux and therefore the use of knock-out-to-wild-type $K \mathrm{p}_{\text {brain }}$ (or $K \mathrm{p}_{\text {uu,brain }}$ ) could also be used as a surrogate metric for efflux. Such an approach improved model predictions of both loperamide $\left(K p_{\text {uu,brain }}=0.025\right)$ and quinidine $\left(K \mathrm{p}_{\text {uu,brain }}=0.071\right)$ to within a 3-fold prediction window (see Supplementary Information Section 6). 
Figure 5. Comparison of predicted and reported $K p_{u u, b r a i n}$ in rat. (A) Solid bold mid-line represents the line of unity and solid outer-lines represent 4-fold prediction error; and $\mathbf{( B )}$ residuals plot.

(A)

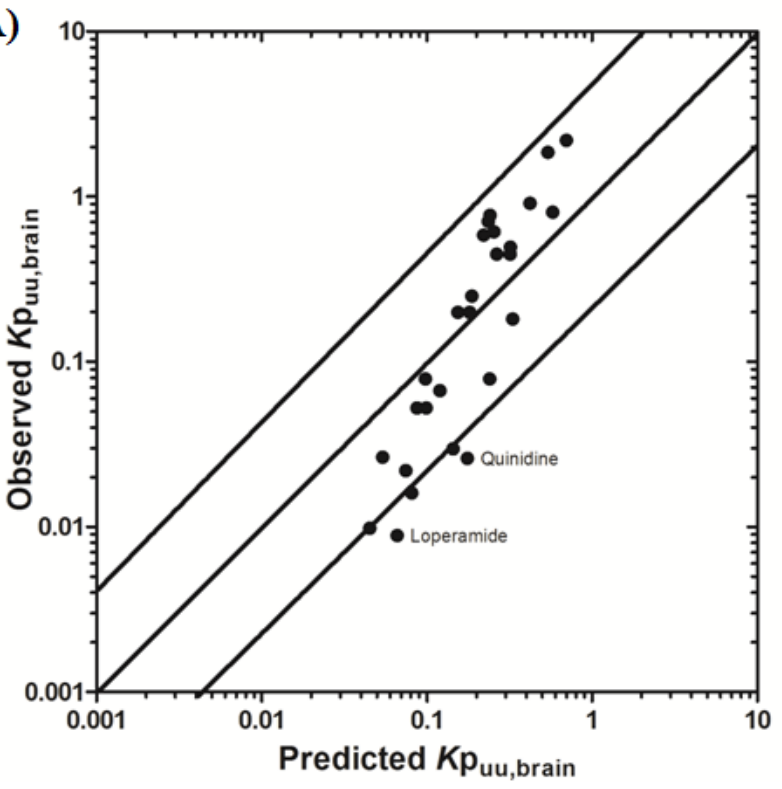

(B)

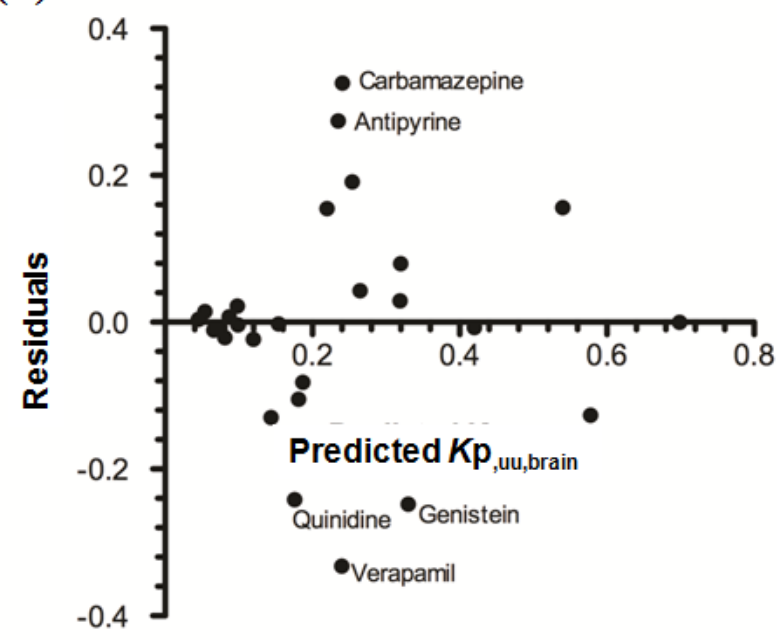

The rat CNS whole-body PBPK model was successful in predicting $\mathrm{CSF}_{\mathrm{u}}$ :Plasma $\mathrm{Pl}_{\mathrm{u}}$ for $81.5 \%$ of compounds to within 4-fold of observed $\mathrm{CSF}_{\mathrm{u}}: \mathrm{Plasma}_{\mathrm{u}}$ (Table 3 and Figure 6A,B), with CSF $\mathrm{Plasma}_{\mathrm{u}}$ of benzylpenicillin 5.8-fold over predicted. The overall afe and rmse were 0.8 and 0.32 respectively (Table 3 ).

Figure 6. Comparison of predicted and reported $\mathrm{CSF}_{\mathrm{u}}: \mathrm{Plasma}_{\mathrm{u}}$ in rat. (A) Solid bold mid-line represents the line of unity and solid outer-lines represent 4-fold prediction error; and $(\mathbf{B})$ residuals plot.

(A)

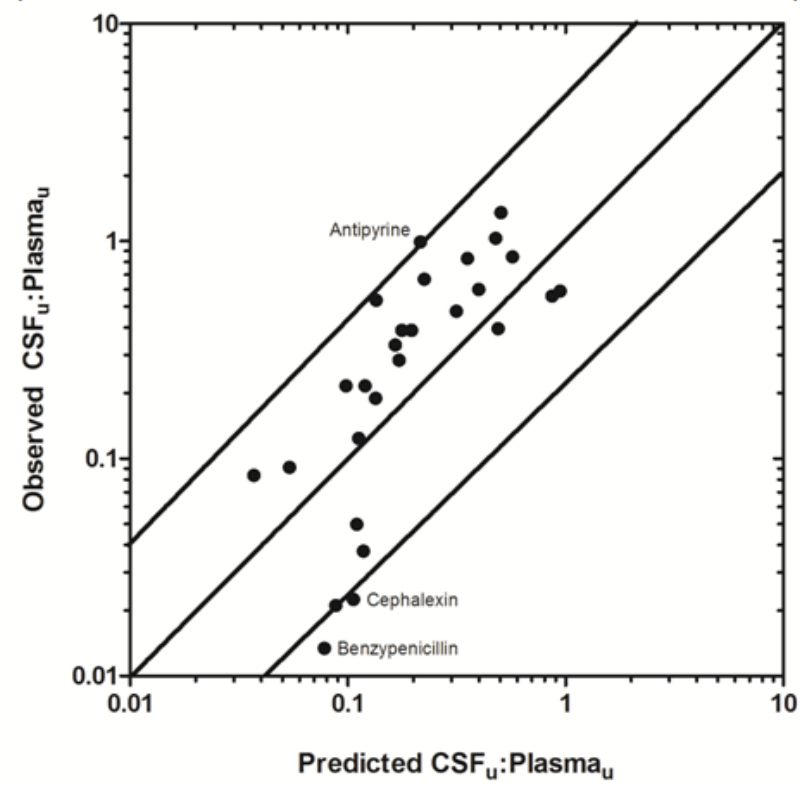

(B)

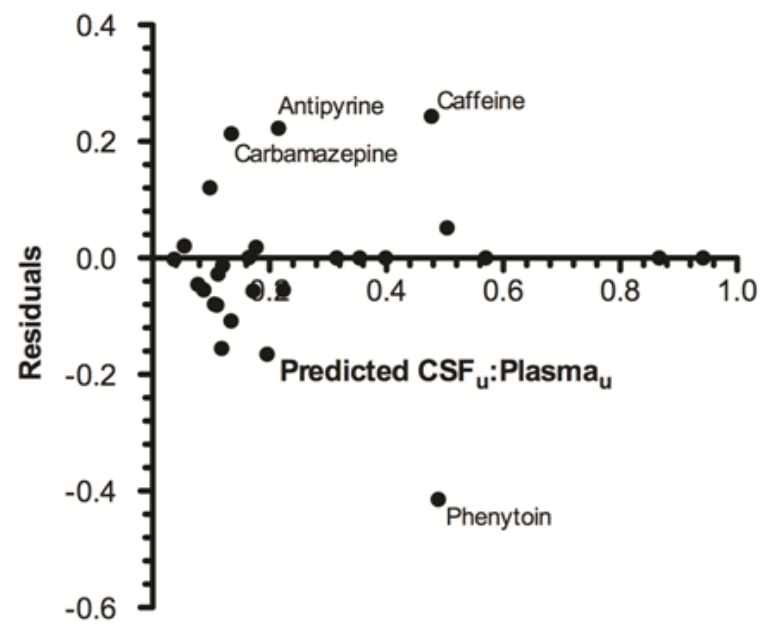




\subsection{Model Sensitivity Analysis}

Several parameters, particularly passive clearance, active efflux, $f \mathrm{u}_{\mathrm{brain}}$ and $f \mathrm{u}_{\text {plasma }}$, have the potential to significantly impact CNS drug distribution by influencing drug clearance across the BBB and BCSFB. To further explore the relationship between drug clearance across the BBB and BCSFB and the extent of protein/tissue binding, risperidone was selected as a model candidate compound and the impact of variation in passive clearance, active efflux, $f \mathrm{u}_{\text {brain }}$ and $f \mathrm{u}_{\mathrm{plasma}}$ on $K \mathrm{p}_{\mathrm{uu} \text {,brain }}$ and $\mathrm{CSF}_{\mathrm{u}}:$ Plasma $_{\mathrm{u}}$ was assessed.

\subsubsection{Passive Clearance}

3.3.1.1. Impact of Variation in $f \mathrm{u}_{\mathrm{plasma}}$ and $f \mathrm{u}_{\mathrm{brain}}$ on $K \mathrm{p}_{\mathrm{uu}, \text { brain }}$ and $\mathrm{CSF}_{\mathrm{u}}: \mathrm{Plasma}_{\mathrm{u}}$

Irrespective of whether the passive clearance $\left(\mathrm{CL}_{\text {passive }}\right)$ (i.e., passive permeability) of risperidone at the BBB and BCSFB was low $\left(\mathrm{CL}_{\text {passive }} 0.34 \mathrm{~mL} / \mathrm{h}\right)$ or high $(64 \mathrm{~mL} / \mathrm{h})$, increasing $f \mathrm{u}_{\text {plasma }}$ (from 0.001 to 1) resulted in a substantial increase in $K \mathrm{p}_{\text {uu,brain }}$ across the range of $f \mathrm{u}_{\text {brain }}(0.001$ to 1$)$ simulated (Figure 7A: transparent mesh indicates high permeability condition; coloured profile indicates low permeability condition).

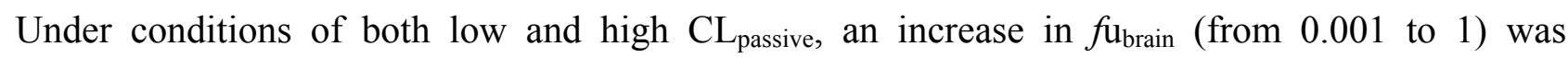
associated with a decrease in brain partitioning $\left(K \mathrm{p}_{\text {uu,brain }}\right)$ of risperidone. This decrease was observed across the range of $f \mathrm{u}_{\text {plasma }}(0.001$ to 1$)$ simulated (Figure 7A: transparent mesh indicates high permeability condition; coloured profile indicates low permeability condition).

Overall, $K \mathrm{p}_{\text {uu,brain }}$ at high $\mathrm{CL}_{\text {passive }}$ was greater than $K \mathrm{p}_{\text {uu,brain }}$ at low $\mathrm{CL}_{\text {passive }}$ when $f \mathrm{u}_{\text {brain }}<0.1$.

Brain penetration is therefore influenced by the extent of plasma protein binding $\left(f u_{\text {plasma }}\right)$ and the extent of drug binding within the brain $\left(f u_{\text {brain }}\right)$. Whilst these observations are relatively intuitive, the importance of both $f u_{\text {plasma }}$ (and hence unbound drug concentration in plasma) and drug permeability across CNS barriers in influencing CNS drug disposition is clearly demonstrated for drugs that exhibit high non-specific binding to brain tissue $\left(f u_{\text {brain }}\right)$. For drugs that are highly bound to brain, $f u_{\text {plasma }}$ drives entry of drug into the brain. Such drugs are retained within the bulk of the brain (bound-unbound cycling) creating a sink effect, and increasing BBB $\mathrm{CL}_{\text {passive }}$ would enhance this sink effect further increasing $K \mathrm{p}_{\text {uu,brain }}$ [98-100].

The disposition of drug into the CSF was demonstrated to be sensitive to $f \mathrm{u}_{\text {plasma, }}$, with increased

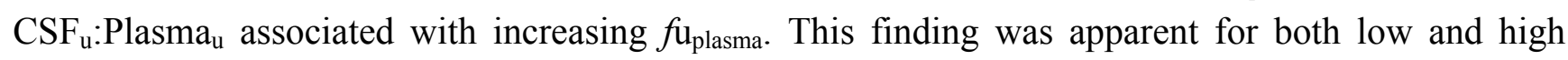
$\mathrm{CL}_{\text {passive }}$ conditions (Figure 7B: transparent mesh indicates high permeability; coloured profile indicates low $\mathrm{CL}_{\text {passive }}$ conditions). However, simulations were insensitive to any change in $f \mathrm{u}_{\text {brain }}$ (0.001-1) (Figure 7B). These simulations demonstrated no apparent relationship between the extent of $f \mathrm{u}_{\text {brain }}$ and $\mathrm{CSF}_{\mathrm{u}}$ :Plasma $\mathrm{u}_{\mathrm{u}}$, suggesting $f \mathrm{u}_{\mathrm{brain}}$ alone does not significantly influence the unbound concentration of drug within the CSF. These findings support the notion that the extent of free drug in plasma is an important factor influencing drug penetration across the BCSFB into the CSF. 
Figure 7. Sensitively analysis of the whole-body physiologically based pharmacokinetic (PBPK) model. The impact of variations in $f u_{\text {brain }}, f u_{\text {plasma }}, \mathrm{CL}_{\text {passive }}$ and efflux ratio on $K \mathrm{p}_{\mathrm{uu}, \text { brain }}$ and $\mathrm{CSF}_{\mathrm{u}}: \mathrm{Plasma}_{\mathrm{u}}$.

(A)

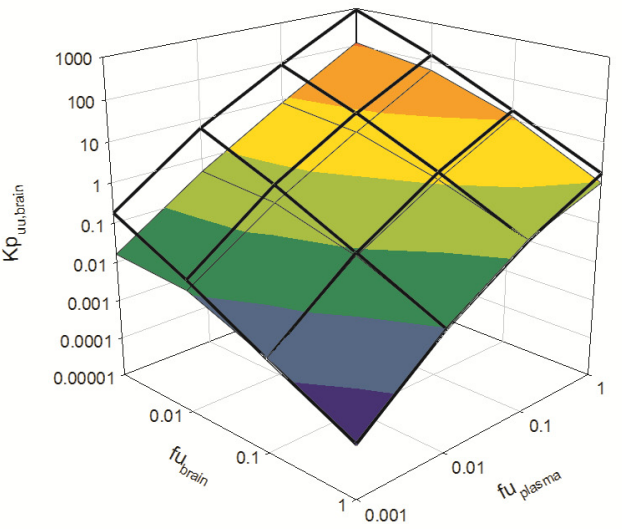

(C)

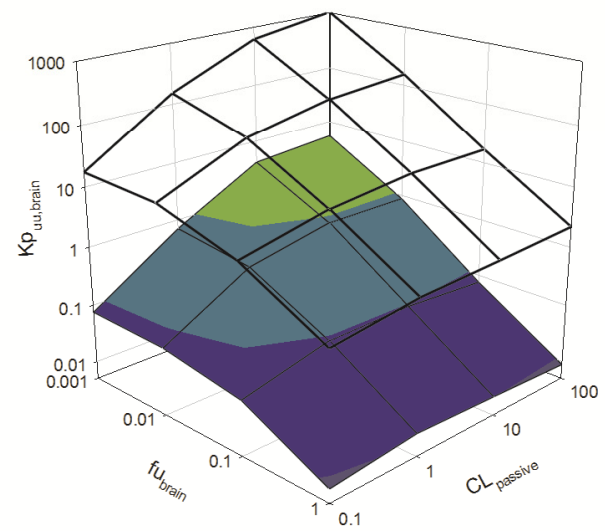

(B)

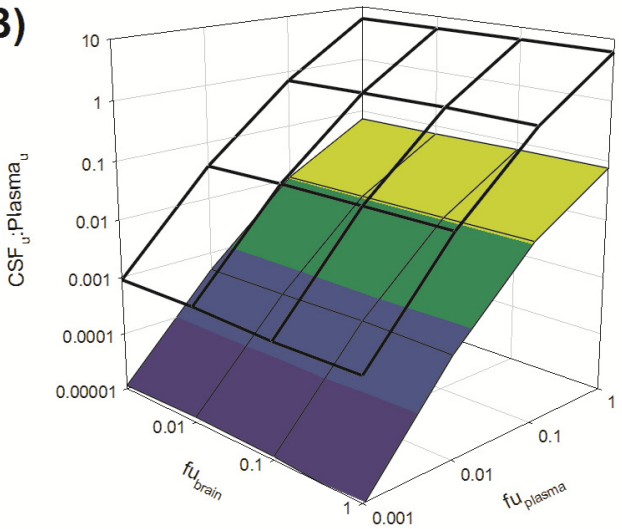

(D)

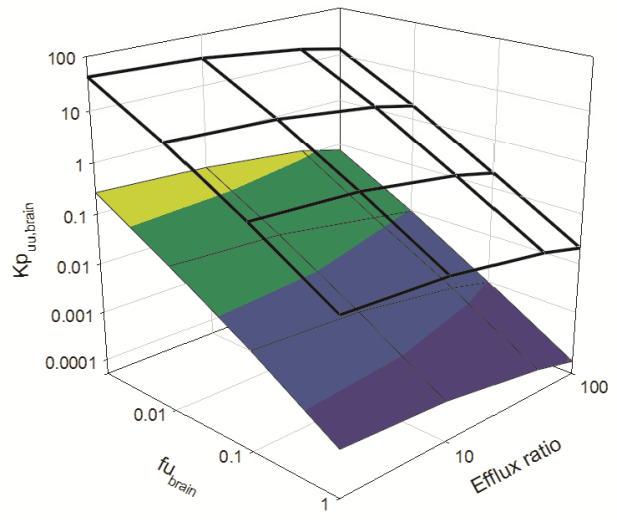

3.3.1.2. Impact of Variation in $f \mathrm{u}_{\text {brain }}$ and $\mathrm{CL}_{\text {passive }}$ on $K \mathrm{p}_{\mathrm{uu}, \text { brain }}$

Irrespective of the extent of plasma protein binding ( $f \mathrm{u}_{\mathrm{plasma}} 0.01$ (low) or 1 (high)), $K \mathrm{p}_{\text {uu,brain }}$ was insensitive to changes in $\mathrm{CL}_{\text {passive }}$ at higher $f \mathrm{u}_{\text {brain }}\left(f \mathrm{u}_{\mathrm{brain}}>0.1\right.$ ) (Figure $7 \mathrm{C}$ : transparent mesh indicates high $f \mathrm{u}_{\text {plasma }}$; coloured profile indicates low high $\left.f \mathrm{u}_{\mathrm{plasma}}\right)$. The sensitivity of $K \mathrm{p}_{\mathrm{uu}, \text { brain }}$ to changes in $\mathrm{CL}_{\text {passive }}$ increased as $f \mathrm{u}_{\text {brain }}$ decreased $(<0.1)$ (Figure $7 \mathrm{C}$ ).

As already established, $f \mathrm{u}_{\text {plasma }}$ determines the unbound plasma drug concentration available to penetrate the $\mathrm{BBB}$ and $\mathrm{BCSBF}$, where higher $f \mathrm{u}_{\text {plasma }}$ results in an increase in the unbound drug concentration available to cross the BBB and BCSFB. Equally, drug binding in brain provides a driving force for retention of drug within the brain mass, which is evident by the increasing $K \mathrm{p}_{\mathrm{uu} \text {,brain }}$ as $f \mathrm{u}_{\text {brain }}$ decreases (irrespective of changes in $\mathrm{CL}_{\text {passive }}$ ). However the important role $f \mathrm{u}_{\text {brain }}$ plays in determining $K \mathrm{p}_{\mathrm{uu} \text {,brain }}$ for highly brain-bound drugs $\left(f \mathrm{u}_{\text {brain }}<0.1\right)$ is particularly evident for lower permeability compounds $\left(\mathrm{CL}_{\text {passive }}<1\right) ; \mathrm{p}_{\mathrm{uu} \text {,brain }}$ appeared not to change significantly when $f \mathrm{u}_{\text {brain }}$ was between 0.001 and 0.1 . However $K \mathrm{p}_{\mathrm{uu} \text {,brain }}$ was reduced when $f \mathrm{u}_{\text {brain }}$ was between 0.1 and 1 (these findings were observed with both high $f \mathrm{u}_{\text {plasma }}$ and low high $f \mathrm{u}_{\text {plasma }}$ conditions). 


\subsubsection{Active Clearance}

\subsubsection{Impact of Variation in $f \mathrm{u}_{\mathrm{brain}}$ and Active Efflux on $K \mathrm{p}_{\mathrm{uu}, \text { brain }}$}

Irrespective of the extent of plasma protein binding ( $f \mathrm{u}_{\text {plasma: }} 0.01$ (low) or 1 (high)), $K \mathrm{p}_{\text {uu,brain }}$ was influenced by variations in both $f u_{\text {brain }}$ over the range studied $\left(f u_{\text {brain }} 0.001-1\right)$ and efflux ratio (2-100) (Figure 7D: transparent mesh indicates high $f \mathrm{u}_{\text {plasma }}$; coloured profile indicates low $f \mathrm{u}_{\text {plasma }}$ ). $K \mathrm{p}_{\mathrm{uu} \text {,brain }}$ increased as $f u_{\text {brain }}$ decreased from 1 to 0.001 , with extensive brain accumulation $\left(K p_{u u, b r a i n}\right.$ greater than 1$)$ when $f u_{\text {plasma }}$ was high $\left(f u_{\text {plasma }}=1\right)$ (Figure 7D).

The increase in $K \mathrm{p}_{\mathrm{uu} \text {,brain }}$ as $f \mathrm{u}_{\text {brain }}$ decreases can be rationalised by considering that $K \mathrm{p}_{\mathrm{uu} \text {,brain }}$ is largely driven by a combination of membrane permeability (passive and active) and drug free fraction in plasma and brain. Where permeability is low $(<0.5 \mathrm{~mL} / \mathrm{h})$ the impact of variation in $f u_{\text {brain }}$ on $K \mathrm{p}_{\text {uu,brain }}$ is limited (Figure $7 \mathrm{C}$ ). When passive permeability increases $\left(\mathrm{CL}_{\text {passive }}>0.5 \mathrm{~mL} / \mathrm{h}\right.$ ), and with increasing active efflux at the BBB (Figure 7D), the extent of dug passive permeability may augment $K \mathrm{p}_{\mathrm{uu}, \text { brain }}$ and counter the impact a reduction in $f \mathrm{u}_{\mathrm{brain}}$ would have on $K \mathrm{p}_{\mathrm{uu}, \text { brain }}$.

\subsubsection{Impact of Variation in $\mathrm{CL}_{\text {passive }}$ and Efflux Ratio on $K \mathrm{p}_{\text {uu,brain }}$}

The extent of non-specific binding of drug in brain $\left(f \mathrm{u}_{\mathrm{brain}}\right)$ had a significant effect on the sensitivity of $K \mathrm{p}_{\text {uu,brain }}$ to $\mathrm{CL}_{\text {passive }}$ and to active efflux (Figure 8). When drug was highly bound in brain (Figure 8A: $f u_{\text {brain }}=0.01$ and $f u_{\text {plasma }}=1$ ), increasing the extent of drug efflux (efflux ratio 2-50) resulted in a

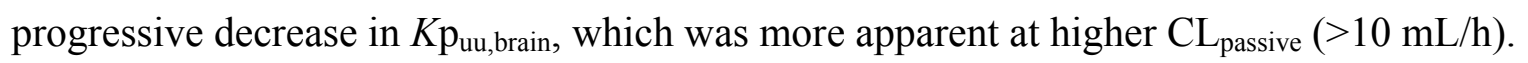

Interestingly, at lower $\mathrm{CL}_{\text {passive }}(<1 \mathrm{~mL} / \mathrm{h})$, increasing the extent of active efflux had minimal effects on $K p_{\text {uu,brain }}$ compared to higher $\mathrm{CL}_{\text {passive }}(>1 \mathrm{~mL} / \mathrm{h})$. This effect was diminished when $f \mathrm{u}_{\text {brain }}$ was high (Figure 8B: $f \mathrm{u}_{\mathrm{brain}}=1$ and $f \mathrm{u}_{\text {plasma }}=1$ ), since $K \mathrm{p}_{\mathrm{uu} \text {,brain }}$ was not sensitive to changes in $\mathrm{CL}_{\text {passive }}$ over a range of efflux ratios (2-50).

Figure 8. Sensitively analysis of the whole-body PBPK model. The impact of variations in $\mathrm{fu}_{\text {brain }}(\mathbf{A})$ low fubrain and (B) high fubrain, $\mathrm{CL}_{\text {passive }}$ and efflux ratio on $K \mathrm{p}_{\text {uu,brain }}$ (see text for details).

(A)

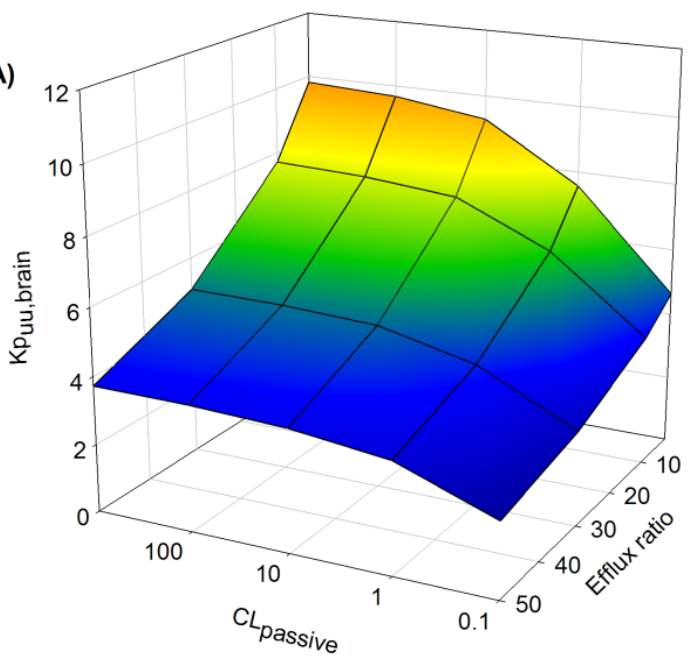

(B)

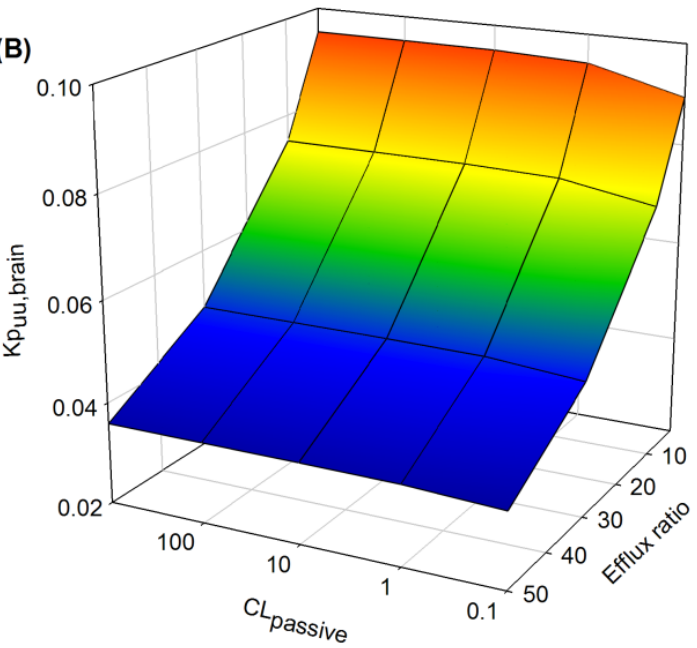


$F \mathrm{u}_{\text {brain }}$ governs the unbound drug concentration in brain and, in conjunction with the clearance of drug across the BBB, helps to regulate the rate and extent of CNS drug accumulation. With extensive non-specific drug binding in brain tissue (Figure $8 \mathrm{~A}$ ), $K \mathrm{p}_{\mathrm{uu}}$,brain was higher than when $f \mathrm{u}_{\text {brain }}$ is not a limiting factor (Figure $8 \mathrm{~B}$ ). In the absence of an efflux effect the sensitivity of $K \mathrm{p}_{\mathrm{uu} \text {,brain }}$ to $f \mathrm{u}_{\text {brain }}$, particularly at low $\mathrm{CL}_{\text {passive }}$ (Figure $8 \mathrm{~A}$ ), may reflect enhancement of the sink effect as drug is readily able to cross the BBB and accumulate within the brain mass with a diminished abluminal-to-luminal clearance. As active efflux increases, this effect is diminished as efflux provides an additional driving force to rebalance the partition of drug between intravascular spaces and brain biophase.

\section{Conclusions}

With development of therapeutic drugs targeted to the CNS lagging behind development of drugs for other therapeutic areas there is an urgent requirement to better predict CNS drug disposition. The application of brain microdialysis and PET imaging techniques will provide a true quantitative understanding of the temporal (regional) brain concentrations, but the techniques and equipment needed for their applications in understanding CNS drug disposition is often a limiting factor to their widespread use.

To address this issue, we have developed a mechanistic, whole-body physiologically-based pharmacokinetic model incorporating both brain biophase (brain ISF) and cerebrospinal fluid compartments, which provided reasonable estimates of brain-to-plasma and CSF-to-plasma ratios using routinely determined experimental parameters (e.g., in vitro permeability, efflux ratio, fu $\mathrm{u}_{\text {plasma }}$ or $f u_{\text {blood }}$ and $\left.f u_{\text {brain }}\right)$. This model not only allows the simultaneous prediction of brain-to-plasma and CSF-to-plasma ratios and examination of the impact of drug permeability and blood flow on CNS drug disposition, but allows a quantitative prediction of unbound drug concentration within the CNS.

Despite the lack of availability of in vitro permeability data from representative in vitro choroid plexus cell models (such as the immortalised Z310 rat cell line [101]), the model adequately predicted CSF-to-plasma ratios for over $90 \%$ of the compounds simulated. The lack of predictive models currently capable of quantifying both brain biophase and CSF drug disposition significantly hinders the assessment of drug disposition within the CNS. Current methods utilising CSF drug kinetics as surrogates for brain drug kinetics remain controversial [95,102], with many studies disagreeing with the use of CSF as a surrogate for brain [103-105]. The physiological differences between the BCSFB and the BBB, advocate the viewpoint that CSF and BCSFB are distinct entities when compared to the BBB. In particular, since CSF drug concentrations do not accurately reflect brain drug concentrations for many actively transported compounds, it is essential that the brain and CSF be considered as separate entities within mechanistic models.

Clearly, in the context of the interactions of drug substrates with transporter proteins, the benefit of the proposed PBPK model would be to effectively incorporate the impact of temporal concentrations on transporter activity and the impact this would have on CNS pharmacokinetics.

The proposed model is capable of predicting temporal CNS drug concentrations, however due to the lack of routinely available transporter-specific Michaelis-Menten terms for drug substrates, the proposed approach of examining overall CNS disposition ( $\mathrm{Kp}_{\mathrm{uu}, \text { brain }}$ and $\left.\mathrm{CSF}_{\mathrm{u}}: \mathrm{Plasma}_{\mathrm{u}}\right)$ is a valid one. In addition, the complexity of modeling the kinetics of drug-transporter protein interaction, at a 
cellular level, is now recognised and could potentially be examined further within the proposed model if BBB and BCSFB cellular compartments were expanded towards a semi-systems biology based model [106]. It is prudent to note however, that such approaches would benefit from the use of microdialysis or PET imaging in combination with more elaborate semi-systems biology models, to aid in the development and validation of models.

The present study reports, for the first time, a PBPK CNS model that predicts $K \mathrm{p}_{\text {uu,brain }}$ and CSF:Plasma (bound and unbound) for compounds possessing diverse pharmacokinetic characteristics. Additionally, this study illustrates the potential use of in vitro L-mdrla-derived permeability data to predict rat CNS drug disposition within an acceptable tolerance.

\section{Acknowledgments}

The authors would like to thank Brian Houston for his advice during the preparation of this manuscript.

\section{Author Contributions}

Conceived and designed the study: R.B. Performed the simulations: R.B. Analysed the data: R.B. and J.P. Provided in-vivo microdialysis data: M.C. Wrote the manuscript: R.B.

\section{Conflicts of Interest}

The authors declare no conflict of interest.

\section{Supplementary Information}

\section{S1. Model Validation: Prediction of Norfloxacin Temporal Brain and Plasma Concentrations in Rats}

Table S1. Model input parameters.

\begin{tabular}{|c|c|c|}
\hline Parameter & Value & Units \\
\hline \multicolumn{3}{|c|}{ Permeability Clearance ${ }^{\mathrm{a}}$} \\
\hline $\begin{array}{l}\mathrm{CL}_{\text {passive }} \\
\text { Efflux }\end{array}$ & Efflux ${ }^{\mathrm{b}}$ & $\mathrm{mL} / \mathrm{h}$ \\
\hline Efflux ratio & 3 & \\
\hline \multicolumn{3}{|c|}{ Unbound fraction } \\
\hline$f u_{\text {plasma }}{ }^{c}$ & 0.78 & \\
\hline$f u_{\text {brain }}{ }^{\mathrm{d}}$ & 1 & \\
\hline$f u_{\mathrm{CSF}}{ }^{\mathrm{e}}$ & 1 & \\
\hline \multicolumn{3}{|c|}{ Physicochemcial } \\
\hline $\log P^{\mathrm{f}}$ & -1.03 & \\
\hline $\mathrm{pKa}^{\mathrm{g}}$ & 6.4 anc & (Zwitterion) \\
\hline \multicolumn{3}{|c|}{ Total plasma clearance } \\
\hline $\mathrm{CL}^{\mathrm{h}}$ & 15.5 & $\mathrm{~mL} / \mathrm{min} / \mathrm{kg}$ \\
\hline
\end{tabular}

${ }^{\mathrm{a}}$ Mean of reported values from Ooie et al. [76]; ${ }^{\mathrm{b}}$ Reported as apical-to-basolateral/basolateral-to-apical flux [107];

${ }^{\mathrm{c}}$ Taken from Ooie et al. [77]; ${ }^{\mathrm{d}}$ Estimated from $V_{\mathrm{u}, \text { brain }}$ [89]; ${ }^{\mathrm{e}}$ Total CSF concentrations were simulated as only CSF:Plasma ${ }_{u}$ have been reported in literature; ${ }^{\mathrm{f}}$ Taken from Hansch et al. [108]; ${ }^{\mathrm{g}}$ Calculated using ChemAxon; and ${ }^{\mathrm{h}}$ Total plasma clearance [88] is split between hepatic (85\%) and renal (15\%) clearance [109]. 
S2. Mouse PBPK Model Compound Specific Parameters

Table S2. Mouse PBPK model parameters.

\begin{tabular}{|c|c|c|c|c|c|c|c|c|c|c|}
\hline \multirow{3}{*}{ Compounds } & \multicolumn{4}{|c|}{ In vitro permeability ${ }^{\mathrm{a}}$} & \multirow{2}{*}{\multicolumn{3}{|c|}{$\begin{array}{l}\text { Active efflux } \\
\text { Efflux ratio }\end{array}$}} & \multicolumn{3}{|c|}{ Permeability clearance } \\
\hline & \multicolumn{2}{|c|}{$\begin{array}{c}P_{\text {app }}(\text { L-mdr1a) } \\
10^{-6} \mathrm{~cm} / \mathrm{s} \\
\end{array}$} & \multicolumn{2}{|c|}{$\begin{array}{c}P_{\text {app }} \text { (LLC-PK1) } \\
10^{-6} \mathrm{~cm} / \mathrm{s}\end{array}$} & & & & \multicolumn{3}{|c|}{$\mathrm{mL} / \mathrm{h}$} \\
\hline & A to $B$ & B to $\mathrm{A}$ & A to $B$ & B to $\mathrm{A}$ & $E R_{\text {functional }}$ & $E R_{\text {non-functional }}$ & $E \boldsymbol{R}_{\text {corrected }}$ & $\mathbf{C L}_{\text {passiveLA }}$ & $\mathrm{CL}_{\text {passiveAL }}$ & $\mathbf{C L}_{\text {active }}$ \\
\hline Quininde & 3.16 & 146 & 57.2 & 80.5 & 46.2 & 1.4 & 30.2 & 14.8 & 20.9 & 447.8 \\
\hline Loperamide & 5.49 & 271 & 49.7 & 98 & 49.4 & 2 & 23 & 12.9 & 25.4 & 296.7 \\
\hline Digoxin & 1.13 & 31.9 & 11.8 & 18.8 & 28.2 & 1.6 & 16.3 & 3.1 & 4.9 & 49.9 \\
\hline Risperdone & 23.3 & 150 & 96.3 & 58.7 & 6.4 & 0.6 & 9.7 & 25 & 15.2 & 242.5 \\
\hline Indindavir & 3.33 & 45.3 & 14.4 & 20.5 & 13.6 & 1.4 & 8.8 & 3.7 & 5.3 & 32.8 \\
\hline Dexamethasone & 6.91 & 102 & 29.5 & 36.5 & 14.8 & 1.2 & 11 & 7.6 & 9.5 & 83.9 \\
\hline Vinblastine & 2.83 & 56.1 & 24.2 & 38.7 & 19.8 & 1.6 & 11.4 & 6.3 & 10 & 71.5 \\
\hline Paclitaxcel & 2.7 & 53.8 & 20.5 & 33.2 & 19.9 & 1.6 & 11.3 & 5.3 & 8.6 & 60.1 \\
\hline Verapamiol & 11.9 & 84 & 73.5 & 39 & 7.1 & 0.5 & 12.2 & 19.1 & 10.1 & 233.2 \\
\hline Loratidine & 32 & 80.2 & 23.1 & 33.1 & 2.5 & 1.4 & 1.6 & 6 & 8.6 & 9.6 \\
\hline Diazepam & 57.3 & 67.2 & 31.8 & 43.5 & 1.2 & 1.4 & 0.8 & 8.2 & 11.3 & 6.5 \\
\hline
\end{tabular}

${ }^{\mathrm{a}}$ Taken from Uchida et al. [55]. 
Table S3. Mouse PBPK metabolic and renal clearance.

\begin{tabular}{|c|c|c|c|c|}
\hline \multirow[b]{2}{*}{ Compounds } & \multicolumn{2}{|l|}{ Metabolic clearance } & \multicolumn{2}{|c|}{ Renal clearance } \\
\hline & $\begin{array}{c}\text { Human }^{\text {a }} \\
\mathrm{CL}_{\text {plasma }} \text { or } \mathrm{CLint}_{\mathrm{u}} \\
\mathrm{mL} / \mathrm{min} / \mathrm{mg} \text { protein or } \mathrm{mL} / \mathrm{min} / \mathrm{kg}\end{array}$ & $\begin{array}{l}\text { Mouse }^{\mathrm{b}} \\
\text { CLint, }_{\text {in vivo }} \\
\mathrm{mL} / \mathrm{min} / \mathrm{kg}\end{array}$ & $\begin{array}{r}\text { Human } \\
\mathrm{C} \\
\mathrm{mL} / \mathrm{m}\end{array}$ & $\begin{array}{l}\text { Mouse } \\
\mathrm{R} \\
\mathrm{in} / \mathrm{kg}\end{array}$ \\
\hline Quininde & 4.02 & 11.02 & 0.8 & 5.28 \\
\hline Loperamide & 0.1775 & 183.56 & na & na \\
\hline Digoxin & 0.07 & 0.08 & $2.06^{\mathrm{c}}$ & 13.596 \\
\hline Risperdone & 5.4 & 10.76 & $12.8^{\mathrm{d}}$ & 84.48 \\
\hline Indindavir & 14.7 & 308.30 & na & na \\
\hline Dexamethasone & 3.91 & 6.31 & na & na \\
\hline Vinblastine & $15.4^{\mathrm{e}}$ & 221.51 & na & na \\
\hline Paclitaxcel & na & $0.54^{\mathrm{f}}$ & na & na \\
\hline Verapamiol & 13.3 & 119.58 & na & na \\
\hline Loratidine & na & na & na & na \\
\hline Diazepam & 0.51 & 1.88 & na & na \\
\hline
\end{tabular}

a unless otherwise indicated, human clearance values were obtained from Hallifax et al. [110]; ${ }^{\mathrm{b}}$ unless otherwise indicated, mouse clearance was determined from human clearance (via calculation of human in vivo intrinsic hepatic clearance) and allometrically scaled (Human $=70 \mathrm{~kg}$, Mouse $=0.020 \mathrm{~kg}$ ), see Section 2.1.1 for further details; ${ }^{\mathrm{c}}$ taken from Hedman et al. (1990) [111]; ${ }^{\mathrm{d}}$ taken from Thyssen et al. [112]; ${ }^{\mathrm{e}}$ taken from Rataom et al. [113]; ${ }^{\mathrm{f}}$ taken from Eiseman et al. [114]; na: not available.

\section{S3. Mouse Brain PBPK Model Predictions}

Table S4. Mouse PBPK model predictions.

\begin{tabular}{cccc}
\hline Compounds & $\begin{array}{c}\text { Predicted } \\
\boldsymbol{K}_{\text {uu,brain }}\end{array}$ & $\begin{array}{c}\text { Observed }^{\text {a }} \\
\boldsymbol{K} \mathbf{p}_{\mathbf{u u}, \text { brain }}\end{array}$ & Fold error \\
\hline Quinidine & 0.034 & 0.058 & 1.7 \\
Loperamide & 0.031 & 0.016 & 1.9 \\
Digoxin & 0.021 & 0.005 & 4.2 \\
Risperidone & 0.315 & 0.212 & 1.4 \\
Indinavir & 0.036 & 0.119 & 3.3 \\
Dexamethasone & 0.031 & 0.093 & 3 \\
Vinblastine & 0.041 & 0.025 & 1.6 \\
Paclitaxel & 0.054 & 0.116 & 2.1 \\
Verapamil & 0.025 & 0.100 & 4 \\
Loratidine & 0.236 & 0.740 & 3.1 \\
Diazepam & 0.588 & 1.160 & 1.9 \\
\hline
\end{tabular}

a Taken from Uchida et al. [55]. 


\section{S4. Rat CNS PBPK Model}

Table S5. Permeability data.

\begin{tabular}{|c|c|c|c|c|c|c|c|c|}
\hline \multirow{3}{*}{ Compounds } & \multirow{3}{*}{ Transporter } & \multirow{2}{*}{\multicolumn{2}{|c|}{$\begin{array}{c}\text { Transporter expressing cells }^{\mathrm{a}} \\
P_{\text {app }}(\mu \mathrm{L} / \mathrm{h} / \text { well })\end{array}$}} & \multirow{2}{*}{\multicolumn{2}{|c|}{$\begin{array}{c}\text { Parental cells } \\
P_{\text {app }}(\mu \mathrm{L} / \mathrm{h} / \text { well }) \\
\end{array}$}} & \multicolumn{3}{|c|}{ Active efflux ${ }^{b}$} \\
\hline & & & & & & & Efflux ratio & \\
\hline & & A to $B$ & B to $A$ & A to $B$ & B to $A$ & $E \boldsymbol{R}_{\text {functional }}$ & $E R_{\text {non-functional }}$ & $E \boldsymbol{R}_{\text {corrected }}$ \\
\hline Antipyrine & & 28.7 & 25.6 & 31.2 & 29.6 & & & \\
\hline Benzypenicillin & & 7.5 & 4.7 & 5.2 & 3.7 & & & \\
\hline Buspirone & & 38.6 & 38.4 & 40.7 & 39.9 & & & \\
\hline Caffeine & & 29.7 & 35.4 & 32.1 & 34.5 & & & \\
\hline Carbamazepine & & 40.6 & 45.2 & 41 & 46.5 & & & \\
\hline Cephalexin & & 4.8 & 3.7 & 4 & 3.7 & & & \\
\hline Citalopram & & 25.9 & 39.2 & 32 & 35.5 & & & \\
\hline Cimetidine & BCRP & 1.8 & 7.2 & 1.2 & 2.4 & 4.0 & 2.0 & 1.8 \\
\hline Daidzen & BCRP & 16.9 & 36.4 & 20.5 & 24.1 & 2.2 & 1.2 & 1.7 \\
\hline Dantrolene & BCRP & 19.9 & 41.9 & 31.1 & 36.1 & 2.1 & 1.2 & 1.7 \\
\hline Diazepam & & 46.5 & 42.2 & 44.4 & 43.7 & & & \\
\hline Flavopiridol & P-gp & 9.6 & 67.3 & 26.6 & 39.6 & 7.0 & 1.5 & 4.3 \\
\hline Flavopiridol & BCRP & 42.9 & 64 & 54.9 & 53.6 & 1.5 & 1.0 & 1.4 \\
\hline Fleroxacin & BCRP & 5.6 & 9.9 & 5.6 & 6.8 & 1.8 & 1.2 & 1.3 \\
\hline Genistein & BCRP & 13.8 & 32.4 & 20.7 & 23.1 & 2.3 & 1.1 & 1.9 \\
\hline Loperamide & P-gp & 12.9 & 54.7 & 22.1 & 15 & 4.2 & 0.7 & 5.7 \\
\hline Midalzolam & & 38.1 & 44.5 & 41.4 & 42.2 & & & \\
\hline Pefloxacin & P-gp & 5.1 & 12.3 & 5.4 & 8.5 & 2.4 & 1.6 & 1.4 \\
\hline Pefloxacin & BCRP & 10.8 & 17.4 & 9 & 9.2 & 1.6 & 1.0 & 1.5 \\
\hline Phenytoin & & 29.6 & 37.1 & 31 & 37.7 & & & \\
\hline Quinidine & P-gp & 6.6 & 42.2 & 22.3 & 22.9 & 6.4 & 1.0 & 5.7 \\
\hline Risperidone & P-gp & 21.3 & 63 & 41.8 & 45.9 & 3.0 & 1.1 & 2.5 \\
\hline Sertraline & & 2.8 & 2.4 & 2.7 & 1.9 & & & \\
\hline Sulpiride & & 2 & 2.7 & 1.9 & 2.4 & & & \\
\hline Thiopental & & 39.6 & 37.7 & 37.1 & 36.4 & & & \\
\hline Verapamil & P-gp & 15.4 & 49 & 24.9 & 23.4 & 3.2 & 0.9 & 3.1 \\
\hline Zolpidem & & 40.3 & 45.8 & 42.4 & 41.6 & & & \\
\hline
\end{tabular}

${ }^{a}$ Compounds known to be subjected to active efflux as a result of a transporter protein are indicated by either BCRP (breast cancer resistance protein or P-gp (P-glycoprotein); and ${ }^{\mathrm{b}}$ calculated only for compounds reported to be subjected to active efflux. 
Table S6. Model predicted versus literature reported in situ permeabilities.

\begin{tabular}{|c|c|c|c|c|c|}
\hline \multirow{3}{*}{ Compounds } & \multirow{3}{*}{ Transporter } & \multicolumn{3}{|c|}{ Permeability clearance } & \multirow{3}{*}{$\begin{array}{c}\text { In } \text { situ } \text { permeability } \\
\text { bL/h }\end{array}$} \\
\hline & & & $\mathbf{m L} / \mathbf{h}$ & & \\
\hline & & $\mathbf{C L}_{\text {passiveLA }}{ }^{\mathrm{a}}$ & CL $\mathbf{L}_{\text {passiveAL }}$ & $\mathbf{C L}_{\text {active }}$ & \\
\hline Antipyrine & & 25.5 & 24.2 & & $66 \pm 2.5[115-117]$ \\
\hline Benzypenicillin & & 4.3 & 3 & & $0.97[118]$ \\
\hline Buspirone & & 33.3 & 32.6 & & \\
\hline Caffeine & & 26.3 & 28.2 & & $95 \pm 33.7[100,115,116,119]$ \\
\hline Carbamazepine & & 10.6 & 33.5 & & $116[96]$ \\
\hline Cephalexin & & 3.3 & 3 & & \\
\hline Citalopram & & 26.2 & 29 & & $67.3[96]$ \\
\hline Cimetidine & BCRP & 2.9 & 16.5 & 5.2 & 0.58 [120] \\
\hline Daidzen & BCRP & $13.5(7)$ & 32 & 23 & $21.6(\mathrm{WT}), 30(-/-)[121]$ \\
\hline Dantrolene & BCRP & $18.4(8.6)$ & 31.6 & 31.3 & $16.7(\mathrm{WT}), 35(-/-)$ [121] \\
\hline Diazepam & & 36.3 & 35.8 & & $351 \pm 254[96,100,122]$ \\
\hline Flavopiridol & P-gp & 21.8 & 32.4 & 181.1 & \\
\hline Flavopiridol & BCRP & 44.9 & 43.9 & 62.9 & \\
\hline Fleroxacin & BCRP & 4.1 & 5 & 5.3 & \\
\hline Genistein & BCRP & 14.6 & 27.1 & 27.7 & \\
\hline Loperamide & P-gp & $18.1(8)$ & 12.3 & 130 & 2 (WT), $26(-/-)[123]$ \\
\hline Midalzolam & & 33.9 & 34.5 & & $459[96]$ \\
\hline Pefloxacin & P-gp & 4.4 & 7 & 7.8 & \\
\hline Pefloxacin & BCRP & 7.4 & 7.5 & 11.1 & \\
\hline Phenytoin & & 25.4 & 30.8 & & $36.7 \pm 21[96,115,124]$ \\
\hline Quinidine & P-gp & 18.2 & 18.7 & 130.7 & $7.45 \pm 6.35[116,120,125]$ \\
\hline Risperidone & P-gp & 34.2 & 37.6 & 107.7 & $101.7[96]$ \\
\hline Sertraline & & 2.2 & 1.6 & & $129[96]$ \\
\hline Sulpiride & & 1.6 & 2 & & \\
\hline Thiopental & & 30.4 & 29.8 & & \\
\hline Verapamil & P-gp & $20.4(10.1)$ & 19.1 & 79.7 & $6 \pm 0.78(\mathrm{WT}) 46.3 \pm 8.42(-/-)[124,126]$ \\
\hline Zolpidem & & 34.7 & 34 & & \\
\hline
\end{tabular}

${ }^{a}$ Permeabilities in italics represent in vivo passive influx in mice and are used in conjunction with the equivalent in situ brain permeability (italics) for correlation purposes; and ${ }^{\mathrm{b}}$ values in italics represent in situ brain permeabilities in mice used for correlation purposes. 
Figure S1. Correlations and confidence interval plots of in situ brain perfusion and predictions of $\mathrm{CL}_{\text {passive. }}$
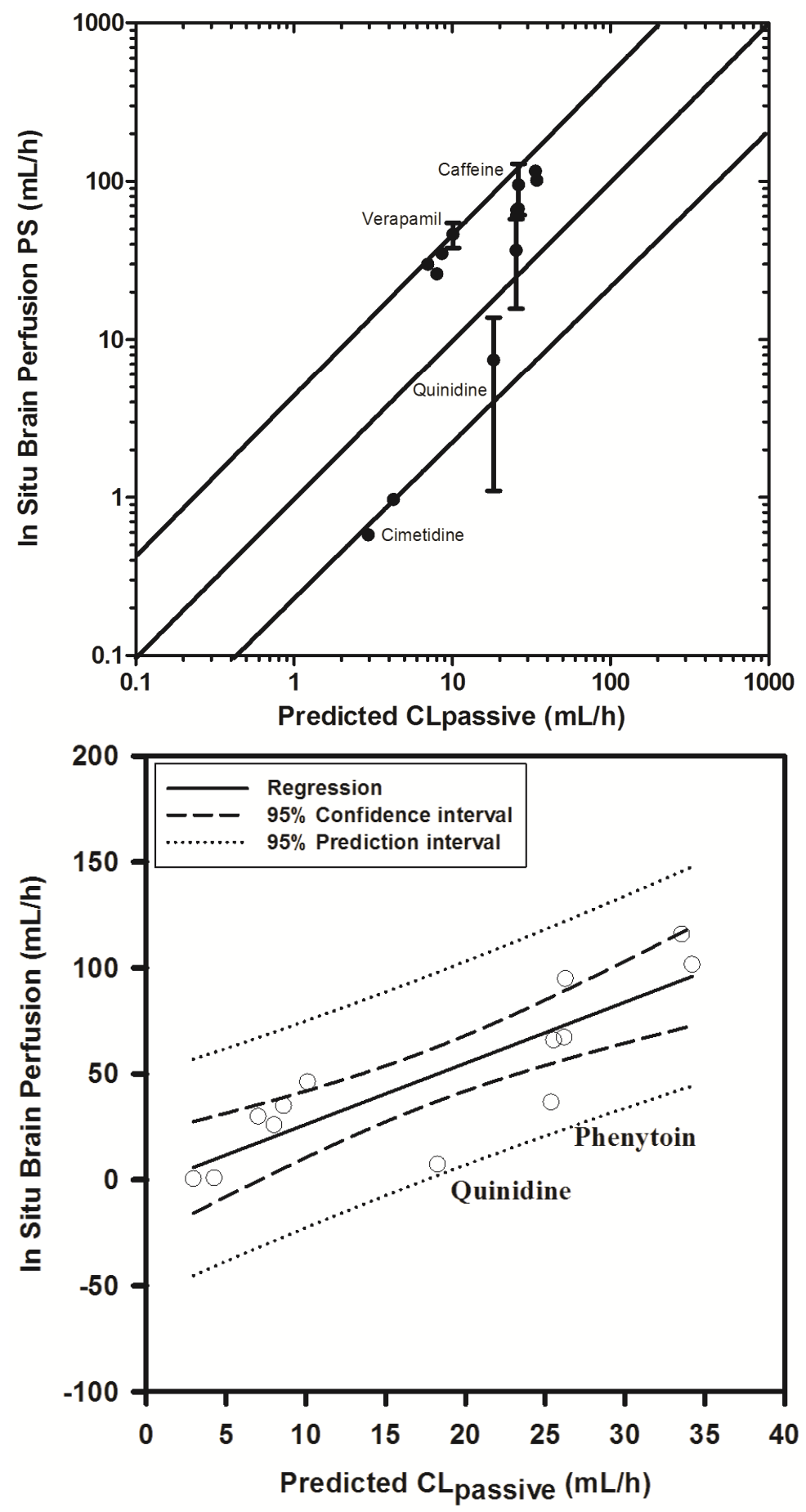
Table S7. Physicochemical parameters used to calculate partition coefficients.

\begin{tabular}{|c|c|c|}
\hline \multirow{2}{*}{ Compounds } & \multicolumn{2}{|c|}{ 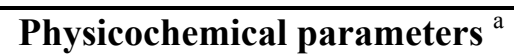 } \\
\hline & pKa & $\log P$ \\
\hline Antipyrine & 1.4 & $0.38^{\mathrm{b}}$ \\
\hline Benzypenicillin & $3.55^{\mathrm{c}}$ & $2.74^{\mathrm{d}}$ \\
\hline Buspirone & 7.62 & $1.95^{\mathrm{e}}$ \\
\hline Caffeine & 14 & $0.92^{\mathrm{f}}$ \\
\hline Carbamazepine & 15.96 & 2.1 \\
\hline Cephalexin & $3.45^{\mathrm{g}}$ & 0.65 \\
\hline Citalopram & 9.78 & 3.5 \\
\hline Cimetidine & $6.8^{\mathrm{h}}$ & 0.26 \\
\hline Daidzen & 8.69 & 0.71 \\
\hline Dantrolene & 7.5 & 1.65 \\
\hline Diazepam & $3.4^{\mathrm{d}}$ & $2.82^{\mathrm{i}}$ \\
\hline Flavopiridol & 5.68 & 2.8 \\
\hline Fleroxacin & 7.15 & 1.84 \\
\hline Genistein & 6.35 & 3.04 \\
\hline Loperamide & 8.6 & 5.5 \\
\hline Midalzolam & 6.2 & 3.89 \\
\hline Pefloxacin & 8.3 & $0.27^{\mathrm{c}}$ \\
\hline Phenytoin & $8.3^{\mathrm{j}}$ & 2.5 \\
\hline Quinidine & 8.56 & $3.4^{\mathrm{c}}$ \\
\hline Risperidone & 8.8 & 2.5 \\
\hline Sertraline & $9.16^{\mathrm{k}}$ & 5.1 \\
\hline Sulpiride & $9.12^{1}$ & 0.57 \\
\hline Thiopental & $7.55^{\mathrm{i}}$ & $2.85^{\mathrm{c}}$ \\
\hline Verapamil & $8.9^{\mathrm{i}}$ & $3.7^{\mathrm{c}}$ \\
\hline Zolpidem & 6.2 & 1.2 \\
\hline
\end{tabular}

Table S8. Protein binding and metabolic clearance.

\begin{tabular}{|c|c|c|c|c|c|}
\hline \multirow[b]{2}{*}{ Compounds } & \multicolumn{3}{|c|}{ Protein Binding a $^{a}$} & \multicolumn{2}{|c|}{ Metabolic Clearance } \\
\hline & $\begin{array}{l}\text { Plasma } \\
f \mathbf{u}_{\text {plasma }}\end{array}$ & $\begin{array}{l}\text { Brain } \\
f \mathbf{u}_{\text {brain }}\end{array}$ & $\begin{array}{l}\mathrm{CSF} \\
f \mathrm{u}_{\mathrm{CSF}}\end{array}$ & $\begin{array}{c}\text { Human }^{b} \\
\mathrm{CL}_{\text {plasma }}(\mathrm{mL} / \mathrm{min} / \mathrm{kg})\end{array}$ & $\begin{array}{c}\operatorname{Rat}^{\mathrm{c}} \\
\mathrm{CL}_{\text {int, in vivo }}(\mathrm{mL} / \mathrm{min} / \mathrm{kg})\end{array}$ \\
\hline Antipyrine & 0.98 & 0.86 & 1 & 0.57 & 0.21 \\
\hline Benzypenicillin & 0.649 & 2.26 & 0.998 & na & na \\
\hline Buspirone & 0.45 & 0.137 & 0.996 & 17.17 & 95.34 \\
\hline Caffeine & 0.917 & 0.697 & 1 & 1.67 & 0.70 \\
\hline Carbamazepine & 0.385 & 0.17 & 0.995 & 0.4 & 0.37 \\
\hline Cephalexin & 1.05 & 1.42 & 1 & na & na \\
\hline Citalopram & 0.82 & 0.437 & 0.999 & 4.5 & 2.50 \\
\hline Cimetidine & 0.529 & 0.0197 & 0.997 & 3.2 & 2.55 \\
\hline Daidzen & 0.0542 & 0.0828 & 0.95 & na & na \\
\hline Dantrolene & 0.117 & 0.0746 & 0.978 & na & na \\
\hline Diazepam & 0.211 & 0.0426 & 0.989 & 0.51 & 0.88 \\
\hline Flavopiridol & 0.254 & 0.0552 & 0.991 & 2.1 & $3.27^{\mathrm{d}}$ \\
\hline Fleroxacin & 0.793 & 0.555 & 0.999 & na & na \\
\hline Genistein & 0.0101 & 0.0531 & 0.773 & na & na \\
\hline Loperamide & 0.0701 & 0.00196 & 0.962 & 0.1775 & 0.90 \\
\hline Midalzolam & 0.045 & 0.0431 & 0.94 & 6.5 & 75.66 \\
\hline Pefloxacin & 0.86 & 0.514 & 1 & na & na \\
\hline Phenytoin & 0.302 & 0.0967 & 0.993 & 0.47 & 0.56 \\
\hline
\end{tabular}


Table S8. Cont.

\begin{tabular}{|c|c|c|c|c|c|}
\hline \multirow[b]{2}{*}{ Compounds } & \multicolumn{3}{|c|}{ Protein Binding ${ }^{\text {a }}$} & \multicolumn{2}{|c|}{ Metabolic Clearance } \\
\hline & $\begin{array}{l}\text { Plasma } \\
f \mathbf{u}_{\text {plasma }}\end{array}$ & $\begin{array}{l}\text { Brain } \\
f \mathbf{u}_{\text {brain }}\end{array}$ & $\begin{array}{r}\mathrm{CSF} \\
f \mathrm{u}_{\mathrm{CSF}}\end{array}$ & $\begin{array}{c}\text { Human }^{\mathrm{b}} \\
\mathrm{CL}_{\text {plasma }}(\mathrm{mL} / \mathrm{min} / \mathrm{kg})\end{array}$ & $\begin{array}{c}\operatorname{Rat}^{\mathrm{c}} \\
C L_{\text {int, in vivo }}(\mathrm{mL} / \mathrm{min} / \mathrm{kg})\end{array}$ \\
\hline Quinidine & 0.454 & 0.0242 & 0.996 & 4.02 & 3.92 \\
\hline Risperidone & 0.158 & 0.0596 & 0.984 & 5.4 & 16.55 \\
\hline Sertraline & 0.0347 & 0.00038 & 0.923 & 27.5 & $158.01^{\mathrm{e}}$ \\
\hline Sulpiride & 0.88 & 0.345 & 1 & 0.08 & $0.03^{f}$ \\
\hline Thiopental & 0.202 & 0.244 & 0.988 & na & na \\
\hline Verapamil & 0.101 & 0.0165 & 0.974 & 13.3 & 138.68 \\
\hline Zolpidem & 0.267 & 0.265 & 0.992 & 4.3 & 7.47 \\
\hline
\end{tabular}

a Taken from Kodaira et al. [53]; ${ }^{\mathrm{b}}$ unless otherwise indicated data was taken from Hallifax et al. [113], as either plasma clearance (denoted by: p) or microsomal clearance (denoted by: $\mathrm{m}$ ); ${ }^{\mathrm{c}}$ unless otherwise indicated, intrinsic in vivo clearance was calculated based on a well stirrer liver model assuming average hepatic blood flow $\left(Q_{\mathrm{H}}, 55 \mathrm{~mL} / \mathrm{min} / \mathrm{kg}\right)$. Blood clearance and unbound fraction in blood were determined using the blood:plasma ratio $\left(R_{\mathrm{b}}\right)$ or by assuming a value of 1 for basic and neutral drugs and 0.55 for acidic drugs; ${ }^{\mathrm{d}}$ taken from Blum et al. [137]; ${ }^{\mathrm{e}}$ calculated from Ronfield et al. [138]; and ${ }^{\mathrm{f}}$ taken from Bres et al. [139]; na: not applicable.

Table S9. Renal clearance. Renal clearance in rats $\left(\mathrm{CL}_{\mathrm{R}}\right)$ was calculated based on glomerular filtration rate (GFR) ratio approach as described by Lin [70].

\begin{tabular}{|c|c|c|}
\hline Comnounds & Human & Rat \\
\hline compotinas & $\mathrm{CL}_{\mathrm{R}}(\mathrm{mL} / \mathrm{min} / \mathrm{kg})$ & $C L_{R}(\mathrm{~mL} / \mathrm{min} / \mathrm{kg})$ \\
\hline Antipyrine & $0.038^{\mathrm{a}}$ & 0.11 \\
\hline Benzypenicillin & $3.52^{b}$ & 10.22 \\
\hline Buspirone & na & na \\
\hline Caffeine & $0.0073^{\mathrm{c}}$ & 0.021 \\
\hline Carbamazepine & na & na \\
\hline Cephalexin & $2.85^{\mathrm{d}}$ & 8.28 \\
\hline Citalopram & na & na \\
\hline Cimetidine & $4.34^{\mathrm{e}}$ & 12.6 \\
\hline Daidzen & na & na \\
\hline Dantrolene & na & na \\
\hline Diazepam & na & na \\
\hline Flavopiridol & na & na \\
\hline Fleroxacin & $0.93^{f}$ & 2.7 \\
\hline Genistein & na & $109^{\mathrm{g}}$ \\
\hline Loperamide & na & na \\
\hline Midalzolam & na & na \\
\hline Pefloxacin & na & na \\
\hline Phenytoin & na & na \\
\hline Quinidine & $0.8^{\mathrm{h}}$ & 2.32 \\
\hline Risperidone & na & na \\
\hline Sertraline & na & na \\
\hline Sulpiride & $1.72^{\mathrm{i}}$ & 4.99 \\
\hline Thiopental & na & na \\
\hline Verapamil & na & na \\
\hline Zolpidem & na & na \\
\hline
\end{tabular}

${ }^{a}$ Taken from Scavone et al. (1989 [140], 1997 [141]) and Thompson et al. [142]; ${ }^{b}$ taken from Rumble et al. [143];

${ }^{\mathrm{c}}$ taken from Birkett and Miners [144]; ${ }^{\mathrm{d}}$ taken from Brogard et al. [145]; ${ }^{\mathrm{e}}$ taken from Larson et al. [146];

${ }^{\mathrm{f}}$ taken from Stuck et al. [147]; ${ }^{\mathrm{g}}$ taken from Setchell et al. [148]; ${ }^{\mathrm{h}}$ taken from Hughes, Ilett and Jellett [149] and Verme et al. [150]; and ${ }^{\mathrm{i}}$ taken from Bres and Bressolle [140]. 


\section{S5. Rat Brain PBPK Model Predictions}

Table S10. Model predictions.

\begin{tabular}{|c|c|c|c|c|c|c|c|}
\hline \multirow{2}{*}{ Compounds } & \multirow{2}{*}{ Transporter } & \multicolumn{3}{|c|}{$K p_{u u, b r a i n}{ }^{\text {a }}$} & \multicolumn{3}{|c|}{$\mathrm{CSF}_{\mathrm{u}}:$ Plasma $_{\mathrm{u}}{ }^{\mathrm{b}}$} \\
\hline & & Predicted & Observed & Fold error & Predicted & Observed & Fold error \\
\hline Antipyrine & & 0.235 & 0.708 & 3.0 & 0.215 & 0.99 & 4.6 \\
\hline Benzypenicillin & & 0.054 & 0.0264 & 2.0 & 0.078 & 0.0134 & 5.8 \\
\hline Buspirone & & 0.254 & 0.612 & 2.4 & 0.867 & 0.558 & 1.6 \\
\hline Caffeine & & 0.220 & 0.584 & 2.7 & 0.477 & 1.03 & 2.2 \\
\hline Carbamazepine & & 0.241 & 0.771 & 3.2 & 0.135 & 0.535 & 4.0 \\
\hline Cephalexin & & 0.078 & 0.016 & 4.8 & 0.106 & 0.0225 & 4.7 \\
\hline Citalopram & & 0.045 & 0.00981 & 4.6 & 0.088 & 0.0211 & 4.1 \\
\hline Cimetidine & BCRP & 0.320 & 0.494 & 1.5 & 0.224 & 0.667 & 3.0 \\
\hline Daidzen & BCRP & 0.120 & 0.0667 & 1.8 & 0.134 & 0.189 & 1.4 \\
\hline Dantrolene & BCRP & 0.144 & 0.0297 & 4.8 & 0.037 & 0.0838 & 2.3 \\
\hline Diazepam & & 0.578 & 0.805 & 1.4 & 0.570 & 0.847 & 1.5 \\
\hline Flavopiridol & P-gp & 0.087 & 0.0525 & 1.7 & 0.120 & 0.216 & 1.8 \\
\hline Flavopiridol & BCRP & 0.079 & 0.0525 & 1.9 & 0.098 & 0.216 & 2.2 \\
\hline Fleroxacin & BCRP & 0.187 & 0.25 & 1.3 & 0.172 & 0.283 & 1.6 \\
\hline Genistein & BCRP & 0.33 & 0.181 & 1.8 & 0.942 & 0.589 & 1.6 \\
\hline Loperamide & P-gp & 0.066 & 0.00886 & 7.4 & 0.118 & 0.0376 & 3.1 \\
\hline Midalzolam & & 0.699 & 2.19 & 3.1 & 0.504 & 1.35 & 2.7 \\
\hline Pefloxacin & P-gp & 0.154 & 0.199 & 1.3 & 0.196 & 0.389 & 2 \\
\hline Pefloxacin & BCRP & 0.181 & 0.199 & 1.1 & 0.177 & 0.389 & 2.2 \\
\hline Phenytoin & & 0.319 & 0.447 & 1.4 & 0.489 & 0.396 & 1.2 \\
\hline Quinidine & P-gp & 0.176 & 0.026 & 6.8 & 0.054 & 0.0911 & 1.7 \\
\hline Risperidone & P-gp & 0.10 & 0.0787 & 1.2 & 0.112 & 0.124 & 1.1 \\
\hline Sertraline & & 0.54 & 1.85 & 3.4 & 0.354 & 0.832 & 2.3 \\
\hline Sulpiride & & 0.07 & 0.0219 & 3.4 & 0.110 & 0.0499 & 2.2 \\
\hline Thiopental & & 0.42 & 0.911 & 2.2 & 0.399 & 0.599 & 1.5 \\
\hline Verapamil & P-gp & 0.24 & 0.0786 & 3.1 & 0.165 & 0.333 & 2 \\
\hline Zolpidem & & 0.27 & 0.447 & 1.7 & 0.315 & 0.475 & 1.5 \\
\hline
\end{tabular}

${ }^{\mathrm{a}, \mathrm{b}}$ Bold indicates parameters predicted with a fold-error $>5$. 
Figure S2. LOESS regression and confidence interval plots.
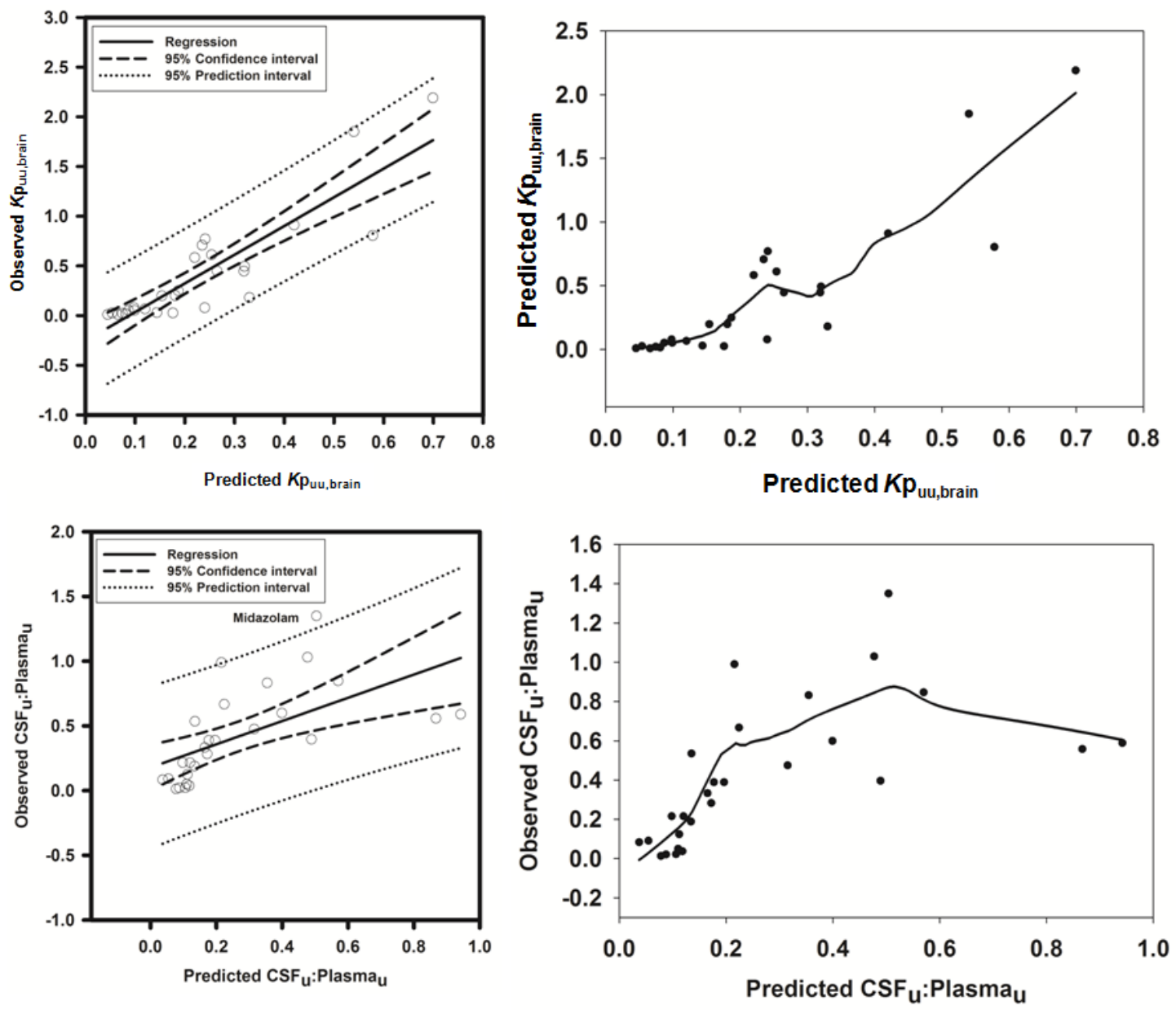

\section{S6. Simulated $K p_{u u, b r a i n}$ and $\mathrm{CSF}_{\mathrm{u}}: \mathbf{P}_{\mathrm{u}}$ for Loperamide and Quinidine}

Figure S3. $K \mathrm{p}_{\text {uu,brain }}$ model predictions for loperamide and quinidine (highlighted in black) using an in vivo surrogate efflux ratio metric for highly effluxed transporter substrates.

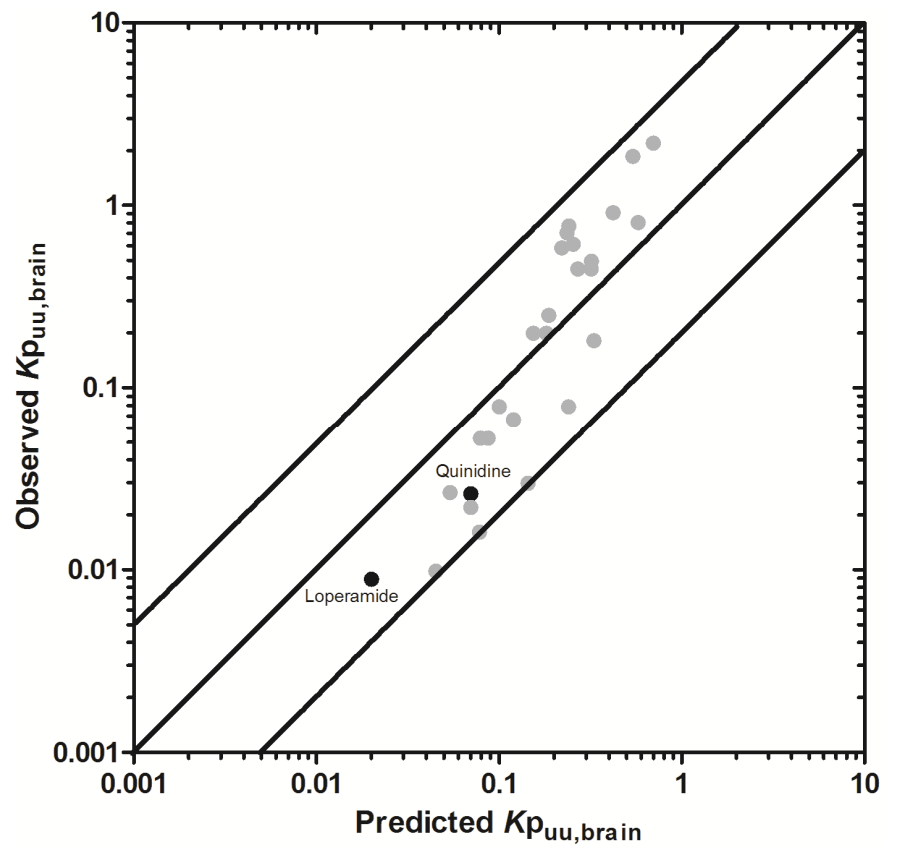




\section{References}

1. Brodie, B.B.; Kurz, H.; Schanker, L.S. The importance of dissociaton constant and lipid-solubility in influencing the passage of drugs into the cerebrospinal fluid. J. Pharmacol. Exp. Ther. 1960, 1, $20-25$.

2. Elmquist, W.F.; Sawchuk, R.J. Application of microdialysis in pharmacokinetic studies. Pharm. Res. 1997, 3, 267-288.

3. Hammarlund-Udenaes, M.; Paalzow, L.K.; de Lange, E.C. Drug equilibration across the blood-brain barrier-Pharmacokinetic considerations based on the microdialysis method. Pharm. Res. 1997, 2, 128-134.

4. Yang, H.; Peters, J.L.; Michael, A.C. Coupled effects of mass transfer and uptake kinetics on in vivo microdialysis of dopamine. J. Neurochem. 1998, 2, 684-692.

5. Syvanen, S.; Lindhe, O.; Palner, M.; Kornum, B.R.; Rahman, O.; Langstrom, B.; Knudsen, G.M.; Hammarlund-Udenaes, M. Species differences in blood-brain barrier transport of three positron emission tomography radioligands with emphasis on P-glycoprotein transport. Drug Metab. Dispos. 2009, 3, 635-643.

6. Friden, M.; Ljungqvist, H.; Middleton, B.; Bredberg, U.; Hammarlund-Udenaes, M. Improved measurement of drug exposure in the brain using drug-specific correction for residual blood. J. Cereb. Blood Flow Metab. 2010, 1, 150-161.

7. Cordon-Cardo, C.; O’Brien, J.P.; Casals, D.; Rittman-Grauer, L.; Biedler, J.L.; Melamed, M.R.; Bertino, J.R. Multidrug-resistance gene (P-glycoprotein) is expressed by endothelial cells at blood-brain barrier sites. Proc. Natl. Acad. Sci. USA 1989, 2, 695-698.

8. Thiebaut, F.; Tsuruo, T.; Hamada, H.; Gottesman, M.M.; Pastan, I.; Willingham, M.C. Immunohistochemical localization in normal tissues of different epitopes in the multidrug transport protein P170: Evidence for localization in brain capillaries and crossreactivity of one antibody with a muscle protein. J. Histochem. Cytochem. 1989, 2, 159-164.

9. Cisternino, S.; Mercier, C.; Bourasset, F.; Roux, F.; Scherrmann, J.-M. Expression, up-regulation, and transport activity of the multidrug-resistance protein Abcg2 at the mouse blood-brain barrier. Cancer Res. 2004, 9, 3296-3301.

10. Sun, H.; Dai, H.; Shaik, N.; Elmquist, W.F. Drug efflux transporters in the CNS. Adv. Drug Deliv. Rev. 2003, 1, 83-105.

11. Uhr, M.; Grauer, M.T. Abcblab P-glycoprotein is involved in the uptake of citalopram and trimipramine into the brain of mice. J. Psychiatr. Res. 2003, 3, 179-185.

12. Wang, J.-S.; Taylor, R.; Ruan, Y.; Donovan, J.L.; Markowitz, J.S.; Lindsay de Vane, C. Olanzapine penetration into brain is greater in transgenic Abcbla P-glycoprotein-deficient mice than FVB1 (wild-type) animals. Neuropsychopharmacology 2004, 3, 551-557.

13. Doran, A.; Obach, R.S.; Smith, B.J.; Hosea, N.A.; Becker, S.; Callegari, E.; Chen, C.; Chen, X.; Choo, E.; Cianfrogna, J.; et al. The impact of P-glycoprotein on the disposition of drugs targeted for indications of the central nervous system: Evaluation using the MDR1A/1B knockout mouse model. Drug Metab. Dispos. 2005, 1, 165-174. 
14. Tahara, H.; Kusuhara, H.; Fuse, E.; Sugiyama, Y. P-glycoprotein plays a major role in the efflux of fexofenadine in the small intestine and blood-brain barrier, but only a limited role in its biliary excretion. Drug Metab. Dispos. 2005, 7, 963-968.

15. Breedveld, P.; Pluim, D.; Cipriani, G.; Wielinga, P.; van Tellingen, O.; Schinkel, A.H.; Schellens, J.H.M. The effect of Bcrp1 (Abcg2) on the in vivo pharmacokinetics and brain penetration of imatinib mesylate (Gleevec): Implications for the use of breast cancer resistance protein and P-glycoprotein inhibitors to enable the brain penetration of imatinib in patients. Cancer Res. 2005, 7, 2577-2582.

16. Ose, A.; Kusuhara, H.; Yamatsugu, K.; Kanai, M.; Shibasaki, M.; Fujita, T.; Yamamoto, A.; Sugiyama, Y. P-glycoprotein restricts the penetration of oseltamivir across the blood-brain barrier. Drug Metab. Dispos. 2008, 2, 427-434.

17. Enokizono, J.; Kusuhara, H.; Sugiyama, Y. Effect of breast cancer resistance protein (Bcrp/Abcg2) on the disposition of phytoestrogens. Mol. Pharmacol. 2007, 4, 967-975.

18. Welch, K.J.; Stewart, W.; Lebowitz, R.L. Non-obstructive megacystis and refuluxing megaureter in pre-teen enuretic boys with minimal symptoms. J. Urol. 1975, 3, 449-454.

19. Saito, Y.; Wright, E.M. Regulation of intracellular chloride in bullfrog choroid plexus. Brain Res. 1987, 2, 267-272.

20. Strazielle, N.; Ghersi-Egea, J.F. Factors affecting delivery of antiviral drugs to the brain. Rev. Med. Virol. 2005, 2, 105-133.

21. Pardridge, W.M. Blood-brain barrier drug targeting: The future of brain drug development. Mol. Interv. 2003, 2, 90-105.

22. Johanson, C.E.; Stopa, E.G.; McMillan, P.N. The blood-cerebrospinal fluid barrier: Structure and functional significance. Methods Mol. Biol. 2011, 686, 101-131.

23. Del Bigio, M.R. The ependyma: A protective barrier between brain and cerebrospinal fluid. Glia 1995, $1,1-13$.

24. Zetterqvist, H. The Ultrastructural Organization of the Columnar Absorbing Cells of the Mouse Jejunum; Aktiebolaget Godvil: Stockholm, Sweden, 1956.

25. Brown, A.L. Microvilli of the human jejunal epithelial cell. J. Cell Biol. 1962, 3, 623-627.

26. Cserr, H.F.; Bundgaard, M.; Ashby, J.K.; Murray, M. On the anatomic relation of choroid plexus to brain: A comparative study. Am. J. Physiol. 1980, 1, R76-R81.

27. Keep, R.F.; Jones, H.C. A morphometric study on the development of the lateral ventricle choroid plexus, choroid plexus capillaries and ventricular ependyma in the rat. Brain Res. Dev. Brain Res. 1990, 1, 47-53.

28. Speake, T.; Brown, P.D. Ion channels in epithelial cells of the choroid plexus isolated from the lateral ventricle of rat brain. Brain Res. 2004, 1-2, 60-66.

29. Ennis, S.R.; Keep, R.F. The effects of cerebral ischemia on the rat choroid plexus. J. Cereb. Blood Flow Metab. 2006, 5, 675-683.

30. Rao, V.V.; Dahlheimer, J.L.; Bardgett, M.E.; Snyder, A.Z.; Finch, R.A.; Sartorelli, A.C.; Piwnica-Worms, D. Choroid plexus epithelial expression of MDR1 P-glycoprotein and multidrug resistance-associated protein contribute to the blood-cerebrospinal-fluid drug-permeability barrier. Proc. Natl. Acad. Sci. USA 1999, 7, 3900-3905. 
31. Zhuang, Y.; Fraga, C.H.; Hubbard, K.E.; Hagedorn, N.; Panetta, J.C.; Waters, C.M.; Stewart, C.F. Topotecan central nervous system penetration is altered by a tyrosine kinase inhibitor. Cancer Res. 2006, 23, 11305-11313.

32. Hammarlund-Udenaes, M. Active-site concentrations of chemicals-Are they a better predictor of effect than plasma/organ/tissue concentrations? Basic Clin. Pharmacol. Toxicol. 2010, 3, 215-220.

33. De Lange, E.C.; Ravenstijn, P.G.; Groenendaal, D.; van Steeg, T.J. Toward the prediction of CNS drug-effect profiles in physiological and pathological conditions using microdialysis and mechanism-based pharmacokinetic-pharmacodynamic modeling. AAPS J. 2005, 3, E532-E543.

34. Friden, M.; Winiwarter, S.; Jerndal, G.; Bengtsson, O.; Wan, H.; Bredberg, U.; Hammarlund-Udenaes, M.; Antonsson, M. Structure-brain exposure relationships in rat and human using a novel data set of unbound drug concentrations in brain interstitial and cerebrospinal fluids. J. Med. Chem. 2009, 20, 6233-6243.

35. Kalvass, J.C.; Maurer, T.S. Influence of nonspecific brain and plasma binding on CNS exposure: Implications for rational drug discovery. Biopharm. Drug Dispos. 2002, 8, 327-338.

36. Reichel, A. Addressing central nervous system (CNS) penetration in drug discovery: Basics and implications of the evolving new concept. Chem. Biodivers. 2009, 11, 2030-2049.

37. Hammarlund-Udenaes, M.; Bredberg, U.; Friden, M. Methodologies to assess brain drug delivery in lead optimization. Curr. Top. Med. Chem. 2009, 2, 148-162.

38. Liu, X.; Smith, B.J.; Chen, C.; Callegari, E.; Becker, S.L.; Chen, X.; Cianfrogna, J.; Doran, A.C.; Doran, S.D.; Gibbs, J.P.; et al. Use of a physiologically based pharmacokinetic model to study the time to reach brain equilibrium: An experimental analysis of the role of blood-brain barrier permeability, plasma protein binding, and brain tissue binding. J. Pharmacol. Exp. Ther. 2005, 3, 1254-1262.

39. Summerfield, S.G.; Dong, K.C. In vitro, in vivo and in silico models of drug distribution into the brain. J. Pharmacokinet. Pharmacodyn. 2013, 3, 301-314.

40. Sadiq, M.W.; Bostrom, E.; Keizer, R.; Bjorkman, S.; Hammarlund-Udenaes, M. Oxymorphone active uptake at the blood-brain barrier and population modeling of its pharmacokineticpharmacodynamic relationship. J. Pharm. Sci. 2013, 102, 3320-3331.

41. Westerhout, J.; Ploeger, B.; Smeets, J.; Danhof, M.; de Lange, E.C. Physiologically based pharmacokinetic modeling to investigate regional brain distribution kinetics in rats. AAPS J. 2012, 3, 543-553.

42. Sadiq, M.W.; Borgs, A.; Okura, T.; Shimomura, K.; Kato, S.; Deguchi, Y.; Jansson, B.; Bjorkman, S.; Terasaki, T.; Hammarlund-Udenaes, M. Diphenhydramine active uptake at the blood-brain barrier and its interaction with oxycodone in vitro and in vivo. J. Pharm. Sci. 2011, 9, 3912-3923.

43. Ball, K.; Bouzom, F.; Scherrmann, J.M.; Walther, B.; Decleves, X. Development of a physiologically based pharmacokinetic model for the rat central nervous system and determination of an in vitro-in vivo scaling methodology for the blood-brain barrier permeability of two transporter substrates, morphine and oxycodone. J. Pharm. Sci. 2012, 11, 4277-4292.

44. Garberg, P.; Ball, M.; Borg, N.; Cecchelli, R.; Fenart, L.; Hurst, R.D.; Lindmark, T.; Mabondzo, A.; Nilsson, J.E.; Raub, T.J.; et al. In vitro models for the blood-brain barrier. Toxicol. In Vitro 2005, 3, 299-334. 
45. Hakkarainen, J.J.; Jalkanen, A.J.; Kaariainen, T.M.; Keski-Rahkonen, P.; Venalainen, T.; Hokkanen, J.; Monkkonen, J.; Suhonen, M.; Forsberg, M.M. Comparison of in vitro cell models in predicting in vivo brain entry of drugs. Int. J. Pharm. 2010, 1-2, 27-36.

46. Neuhaus, W.; Stessl, M.; Strizsik, E.; Bennani-Baiti, B.; Wirth, M.; Toegel, S.; Modha, M.; Winkler, J.; Gabor, F.; Viernstein, H.; et al. Blood-brain barrier cell line PBMEC/C1-2 possesses functionally active P-glycoprotein. Neurosci. Lett. 2010, 2, 224-228.

47. Roux, F.; Couraud, P.-O. Rat brain endothelial cell lines for the study of blood-brain barrier permeability and transport functions. Cell. Mol. Neurobiol. 2005, 1, 41-58.

48. Patabendige, A.; Skinner, R.A.; Morgan, L.; Joan Abbott, N. A detailed method for preparation of a functional and flexible blood-brain barrier model using porcine brain endothelial cells. Brain Res. 2013, 1521, 16-30.

49. Patabendige, A.; Skinner, R.A.; Abbott, N.J. Establishment of a simplified in vitro porcine blood-brain barrier model with high transendothelial electrical resistance. Brain Res. 2013, 1521, $1-15$.

50. Lundquist, S.; Renftel, M.; Brillault, J.; Fenart, L.; Cecchelli, R.; Dehouck, M.P. Prediction of drug transport through the blood-brain barrier in vivo: A comparison between two in vitro cell models. Pharm. Res. 2002, 7, 976-981.

51. Nicolazzo, J.A.; Charman, S.A.; Charman, W.N. Methods to assess drug permeability across the blood-brain barrier. J. Pharm. Pharmacol. 2006, 3, 281-293.

52. Reichel, A.; Begley, D.J.; Abbott, N.J. An overview of in vitro techniques for blood-brain barrier studies. Methods Mol. Med. 2003, 89, 307-324.

53. Kodaira, H.; Kusuhara, H.; Fujita, T.; Ushiki, J.; Fuse, E.; Sugiyama, Y. Quantitative evaluation of the impact of active efflux by P-glycoprotein and breast cancer resistance protein at the blood-brain barrier on the predictability of the unbound concentrations of drugs in the brain using cerebrospinal fluid concentration as a surrogate. J. Pharmacol. Exp. Ther. 2011, 3, 935-944.

54. Uchida, Y.; Ohtsuki, S.; Katsukura, Y.; Ikeda, C.; Suzuki, T.; Kamiie, J.; Terasaki, T. Quantitative targeted absolute proteomics of human blood-brain barrier transporters and receptors. J. Control. Release 2011, 2, 333-345.

55. Uchida, Y.; Ohtsuki, S.; Kamiie, J.; Terasaki, T. Blood-brain barrier (BBB) pharmacoproteomics: Reconstruction of in vivo brain distribution of 11 P-glycoprotein substrates based on the BBB transporter protein concentration, in vitro intrinsic transport activity, and unbound fraction in plasma and brain in mice. J. Pharmacol. Exp. Ther. 2011, 2, 579-588.

56. Kamiie, J.; Ohtsuki, S.; Iwase, R.; Ohmine, K. Quantitative atlas of membrane transporter proteins: Development and application of a highly sensitive simultaneous LC/MS/MS method combined with novel in silico peptide selection criteria. Pharm. Res. 2008, 25, 1469-1483.

57. Hoshi, Y.; Uchida, Y.; Tachikawa, M.; Inoue, T.; Ohtsuki, S.; Terasaki, T. Quantitative atlas of blood-brain barrier transporters, receptors, and tight junction proteins in rats and common marmoset. J. Pharm. Sci. 2013, 102, 3343-3355.

58. Brown, R.P.; Delp, M.D.; Lindstedt, S.L.; Rhomberg, L.R.; Beliles, R.P. Physiological parameter values for physiologically based pharmacokinetic models. Toxicol. Ind. Health 1997, 4, 407-484.

59. Rodgers, T.; Leahy, D.; Rowland, M. Physiologically based pharmacokinetic modeling 1: Predicting the tissue distribution of moderate-to-strong bases. J. Pharm. Sci. 2005, 6, 1259-1276. 
60. Rodgers, T.; Rowland, M. Physiologically based pharmacokinetic modelling 2: Predicting the tissue distribution of acids, very weak bases, neutrals and zwitterions. J. Pharm. Sci. 2006, 6, 1238-1257.

61. Bois, F.Y. Statistical analysis of Fisher et al. PBPK model of trichloroethylene kinetics. Environ. Health Perspect. 2000, 108, 275-282.

62. West, G.B.; Brown, J.H.; Enquist, B.J. A general model for the origin of allometric scaling laws in biology. Science 1997, 5309, 122-126.

63. Meno-Tetang, G.M.L.; Li, H.; Mis, S.; Pyszczynski, N.; Heining, P.; Lowe, P.; Jusko, W.J. Physiologically based pharmacokinetic modeling of FTY720 (2-amino-2[2-(-4-octylphenyl)ethyl] propane-1,3-diol hydrochloride) in rats after oral and intravenous doses. Drug Metab. Dispos. 2006, 9, 1480-1487.

64. Davies, B.; Morris, T. Physiological parameters in laboratory animals and humans. Pharm. Res. 1993, 7, 1093-1095.

65. Eyal, S.; Ke, B.; Muzi, M.; Link, J.M.; Mankoff, D.A.; Collier, A.C.; Unadkat, J.D. Regional P-glycoprotein activity and inhibition at the human blood-brain barrier as imaged by positron emission tomography. Clin. Pharmacol. Ther. 2010, 5, 579-585.

66. Stange, K.; Greitz, D.; Ingvar, M.; Hindmarsh, T.; Sollevi, A. Global cerebral blood flow during infusion of adenosine in humans: Assessment by magnetic resonance imaging and positron emission tomography. Acta Physiol. Scand. 1997, 2, 117-122.

67. Jay, T.M.; Lucignani, G.; Crane, A.M.; Jehle, J.; Sokoloff, L. Measurement of local cerebral blood flow with $\left[{ }^{14} \mathrm{C}\right]$ iodoantipyrine in the mouse. J. Cereb. Blood Flow Metab. 1988, 1, 121-129.

68. Abbott, N.J. Evidence for bulk flow of brain interstitial fluid: Significance for physiology and pathology. Neurochem. Int. 2004, 4, 545-552.

69. Johnson, M.D.; Anderson, B.D. In vitro models of the blood-brain barrier to polar permeants: Comparison of transmonolayer flux measurements and cell uptake kinetics using cultured cerebral capillary endothelial cells. J. Pharm. Sci. 1999, 6, 620-625.

70. Lin, J.H. Applications and limitations of interspecies scaling and in vitro extrapolation in pharmacokinetics. Drug Metab. Dispos. 1998, 12, 1202-1212.

71. Houston, J.B. Utility of in vitro drug metabolism data in predicting in vivo metabolic clearance. Biochem. Pharmacol. 1994, 9, 1469-1479.

72. Iwatsubo, T.; Suzuki, H.; Shimada, N.; Chiba, K.; Ishizaki, T.; Green, C.E.; Tyson, C.A.; Yokoi, T.; Kamataki, T.; Sugiyama, Y. Prediction of in vivo hepatic metabolic clearance of YM796 from in vitro data by use of human liver microsomes and recombinant P-450 isozymes. J. Pharmacol. Exp. Ther. 1997, 2, 909-919.

73. Bayliss, M.K.; Bell, J.A.; Jenner, W.N.; Wilson, K. Prediction of intrinsic clearance of loxtidine from kinetic studies in rat, dog and human hepatocytes. Biochem. Soc. Trans. 1990, 6, 1198-1199.

74. Bank, N.; Aynedjian, H.S.; Qiu, J.H.; Osei, S.Y.; Ahima, R.S.; Fabry, M.E.; Nagel, R.L. Renal nitric oxide synthases in transgenic sickle cell mice. Kidney Int. 1996, 1, 184-189.

75. Hammarlund-Udenaes, M.; Friden, M.; Syvanen, S.; Gupta, A. On the rate and extent of drug delivery to the brain. Pharm. Res. 2008, 8, 1737-1750.

76. Ooie, T.; Terasaki, T.; Suzuki, H.; Sugiyama, Y. Kinetic evidence for active efflux transport across the blood-brain barrier of quinolone antibiotics. J. Pharmacol. Exp. Ther. 1997, 1, 293-304. 
77. Ooie, T.; Terasaki, T.; Suzuki, H.; Sugiyama, Y. Quantitative brain microdialysis study on the mechanism of quinolones distribution in the central nervous system. Drug Metab. Dispos. 1997, 7, 784-789.

78. Grabb, P.A.; Gilbert, M.R. Neoplastic and pharmacological influence on the permeability of an in vitro blood-brain barrier. J. Neurosurg. 1995, 6, 1053-1058.

79. Stanness, K.A.; Neumaier, J.F.; Sexton, T.J.; Grant, G.A.; Emmi, A.; Maris, D.O.; Janigro, D. A new model of the blood-brain barrier: Co-culture of neuronal, endothelial and glial cells under dynamic conditions. Neuroreport 1999, 18, 3725-3731.

80. Parkinson, F.E.; Friesen, J.; Krizanac-Bengez, L.; Janigro, D. Use of a three-dimensional in vitro model of the rat blood-brain barrier to assay nucleoside efflux from brain. Brain Res. 2003, 2, 233-241.

81. Parkinson, F.E.; Hacking, C. Pericyte abundance affects sucrose permeability in cultures of rat brain microvascular endothelial cells. Brain Res. 2005, 1, 8-14.

82. Perriere, N.; Yousif, S.; Cazaubon, S.; Chaverot, N.; Bourasset, F.; Cisternino, S.; Decleves, X.; Hori, S.; Terasaki, T.; Deli, M.; et al. A functional in vitro model of rat blood-brain barrier for molecular analysis of efflux transporters. Brain Res. 2007, 1150, 1-13.

83. Strazielle, N.; Ghersi-Egea, J.F. Demonstration of a coupled metabolism-efflux process at the choroid plexus as a mechanism of brain protection toward xenobiotics. J. Neurosci. 1999, 15, 6275-6289.

84. Hoffmeyer, S.; Burk, O.; von Richter, O.; Arnold, H.P.; Brockmoller, J.; Johne, A.; Cascorbi, I.; Gerloff, T.; Roots, I.; Eichelbaum, M.; et al. Functional polymorphisms of the human multidrug-resistance gene: Multiple sequence variations and correlation of one allele with P-glycoprotein expression and activity in vivo. Proc. Natl. Acad. Sci. USA 2000, 7, 3473-3478.

85. Shirasaka, Y.; Sakane, T.; Yamashita, S. Effect of P-glycoprotein expression levels on the concentration-dependent permeability of drugs to the cell membrane. J. Pharm. Sci. 2008, 1, 553-565.

86. Tachibana, T.; Kitamura, S.; Kato, M.; Mitsui, T.; Shirasaka, Y.; Yamashita, S.; Sugiyama, Y. Model analysis of the concentration-dependent permeability of P-gp substrates. Pharm. Res. 2010, 3, 442-446.

87. Adachi, Y.; Suzuki, H.; Sugiyama, Y. Comparative studies on in vitro methods for evaluating in vivo function of MDR1 P-glycoprotein. Pharm. Res. 2001, 12, 1660-1668.

88. Chenel, M.; Marchand, S.; Dupuis, A.; Lamarche, I.; Paquereau, J.; Pariat, C.; Couet, W. Simultaneous central nervous system distribution and pharmacokinetic-pharmacodynamic modelling of the electroencephalogram effect of norfloxacin administered at a convulsant dose in rats. Br. J. Pharmacol. 2004, 2, 323-330.

89. Friden, M.; Gupta, A.; Antonsson, M.; Bredberg, U.; Hammarlund-Udenaes, M. In vitro methods for estimating unbound drug concentrations in the brain interstitial and intracellular fluids. Drug Metab. Dispos. 2007, 9, 1711-1719.

90. Reinoso, R.F.; Telfer, B.A.; Rowland, M. Tissue water content in rats measured by desiccation. J. Pharmacol. Toxicol. Methods 1997, 2, 87-92. 
91. Fenneteau, F.; Turgeon, J.; Couture, L.; Michaud, V.; Li, J.; Nekka, F. Assessing drug distribution in tissues expressing P-glycoprotein through physiologically based pharmacokinetic modeling: Model structure and parameters determination. Theor. Biol. Med. Model. 2009, 6, 2:1-2:13.

92. Polli, J.W.; Humphreys, J.E.; Wring, S.A.; Burnette, T.C. A comparison of Madin-Darby canine kidney cells and bovine brain endothelial cells as a blood-brain barrier screen in early drug discovery. In Progress in the Reduction, Refinement and Replacement of Animal Experimentation; Balls, M., van Zeller, A.M., Halder, M.E., Eds.; Elsevier Sciences: Amsterdam, The Netherlands, 2000; pp. 271-289.

93. Merino, G.; Alvarez, A.I.; Pulido, M.M.; Molina, A.J.; Schinkel, A.H.; Prieto, J.G. Breast cancer resistance protein (BCRP/ABCG2) transports fluoroquinolone antibiotics and affects their oral availability, pharmacokinetics, and milk secretion. Drug Metab. Dispos. 2006, 4, 690-695.

94. Delon, A.; Pariat, C.; Courtois, P.; Bouquet, S.; Couet, W. A new approach for early assessment of the epileptogenic potential of quinolones. Antimicrob. Agents Chemother. 1998, 10, 2756-2758.

95. Liu, X.; Smith, B.J.; Chen, C.; Callegari, E.; Becker, S.L.; Chen, X.; Cianfrogna, J.; Doran, A.C.; Doran, S.D.; Gibbs, J.P.; et al. Evaluation of cerebrospinal fluid concentration and plasma free concentration as a surrogate measurement for brain free concentration. Drug Metab. Dispos. 2006, 9, 1443-1447.

96. Summerfield, S.G.; Read, K.; Begley, D.J.; Obradovic, T.; Hidalgo, I.J.; Coggon, S.; Lewis, A.V.; Porter, R.A.; Jeffrey, P. Central nervous system drug disposition: The relationship between in situ brain permeability and brain free fraction. J. Pharmacol. Exp. Ther. 2007, 1, 205-213.

97. Kalvass, J.C.; Maurer, T.S.; Pollack, G.M. Use of plasma and brain unbound fractions to assess the extent of brain distribution of 34 drugs: Comparison of unbound concentration ratios to in vivo P-glycoprotein efflux ratios. Drug Metab. Dispos. 2007, 4, 660-666.

98. Urien, S.; Pinquier, J.L.; Paquette, B.; Chaumet-Riffaud, P.; Kiechel, J.R.; Tillement, J.P. Effect of the binding of isradipine and darodipine to different plasma proteins on their transfer through the rat blood-brain barrier. Drug binding to lipoproteins does not limit the transfer of drug. J. Pharmacol. Exp. Ther. 1987, 1, 349-353.

99. Jolliet, P.; Simon, N.; Bree, F.; Urien, S.; Pagliara, A.; Carrupt, P.A.; Testa, B.; Tillement, J.P. Blood-to-brain transfer of various oxicams: Effects of plasma binding on their brain delivery. Pharm. Res. 1997, 5, 650-656.

100. Tanaka, H.; Mizojiri, K. Drug-protein binding and blood-brain barrier permeability. J. Pharmacol. Exp. Ther. 1999, 3, 912-918.

101. Zheng, W.; Zhao, Q. Establishment and characterization of an immortalized Z310 choroidal epithelial cell line from murine choroid plexus. Brain Res. 2002, 2, 371-380.

102. Shen, D.D.; Artru, A.A.; Adkison, K.K. Principles and applicability of CSF sampling for the assessment of CNS drug delivery and pharmacodynamics. Adv. Drug Deliv. Rev. 2004, 12, $1825-1857$.

103. Wong, S.L.; Wang, Y.; Sawchuk, R.J. Analysis of zidovudine distribution to specific regions in rabbit brain using microdialysis. Pharm. Res. 1992, 3, 332-338.

104. Van Amsterdam, C.; Lemaire, M. Pharmacokinetic profile of SDZ EAA 494 in blood, brain and CSF using microdialysis. Eur. J. Pharm. Sci. 1997, 2, 109-116. 
105. Hammarlund-Udenaes, M. The use of microdialysis in CNS drug delivery studies. Pharmacokinetic perspectives and results with analgesics and antiepileptics. Adv. Drug Del. Rev. 2000, 2-3, 283-294.

106. Sjostedt, N.; Kortejarvi, H.; Kidron, H.; Vellonen, K.S.; Urtti, A.; Yliperttula, M. Challenges of using in vitro data for modeling P-glycoprotein efflux in the blood-brain barrier. Pharm. Res. 2014, 31, 1-19.

107. Griffiths, N.M.; Hirst, B.H.; Simmons, N.L. Active intestinal secretion of the fluoroquinolone antibacterials ciprofloxacin, norfloxacin and pefloxacin; a common secretory pathway? J. Pharmacol. Exp. Ther. 1994, 2, 496-502.

108. Hansch, C.; Leo, A.; Hoekman, D.H. Exploring QSAR.: Fundamentals and Applications in Chemistry and Biology; American Chemical Society: Washington, DC, USA, 1995.

109. Davis, J.D.; Aarons, L.; Houston, J.B. Effect of norfloxacin on theophylline disposition: A comparison with other fluoroquinolones. Pharm. Res. 1995, 2, 257-262.

110. Hallifax, D.; Foster, J.A.; Houston, J.B. Prediction of human metabolic clearance from in vitro systems: Retrospective analysis and prospective view. Pharm. Res. 2010, 10, 2150-2161.

111. Hedman, A.; Angelin, B.; Arvidsson, A.; Dahlqvist, R.; Nilsson, B. Interactions in the renal and biliary elimination of digoxin: Stereoselective difference between quinine and quinidine. Clin. Pharmacol. Ther. 1990, 1, 20-26.(112)

112. Thyssen, A.; Vermeulen, A.; Fuseau, E.; Fabre, M.A.; Mannaert, E. Population pharmacokinetics of oral risperidone in children, adolescents and adults with psychiatric disorders. Clin. Pharmacokinet. 2010, 7, 465-478.

113. Ratain, M.J.; Vogelzang, N.J.; Sinkule, J.A. Interpatient and intrapatient variability in vinblastine pharmacokinetics. Clin. Pharmacol. Ther. 1987, 1, 61-67.(114)

114. Eiseman, J.L.; Eddington, N.D.; Leslie, J.; MacAuley, C.; Sentz, D.L.; Zuhowski, M.; Kujawa, J.M.; Young, D.; Egorin, M.J. Plasma pharmacokinetics and tissue distribution of paclitaxel in CD2F1 mice. Cancer Chemother. Pharmacol. 1994, 6, 465-471. (111)

115. Takasato, Y.; Rapoport, S.I.; Smith, Q.R. An in situ brain perfusion technique to study cerebrovascular transport in the rat. Am. J. Physiol. 1984, 3, H484-H493.

116. Liu, X.; Tu, M.; Kelly, R.S.; Chen, C.; Smith, B.J. Development of a computational approach to predict blood-brain barrier permeability. Drug Metab. Dispos. 2004, 1, 132-139.

117. Gratton, J.A.; Abraham, M.H.; Bradbury, M.W.; Chadha, H.S. Molecular factors influencing drug transfer across the blood-brain barrier. J. Pharm. Pharmacol. 1997, 12, 1211-1216.

118. Suzuki, H.; Sawada, Y.; Sugiyama, Y.; Iga, T.; Hanano, M. Facilitated transport of benzylpenicillin through the blood-brain barrier in rats. J. Pharmacobiodyn. 1989, 3, 182-185.

119. Rapoport, S.I.; Ohno, K.; Pettigrew, K.D. Drug entry into the brain. Brain Res. 1979, 2, 354-359.

120. Murakami, H.; Takanaga, H.; Matsuo, H.; Ohtani, H.; Sawada, Y. Comparison of blood-brain barrier permeability in mice and rats using in situ brain perfusion technique. Am. J. Physiol. Heart Circ. Physiol. 2000, 3, H1022-H1028.

121. Enokizono, J.; Kusuhara, H.; Ose, A.; Schinkel, A.H.; Sugiyama, Y. Quantitative investigation of the role of breast cancer resistance protein (Bcrp/Abcg2) in limiting brain and testis penetration of xenobiotic compounds. Drug Metab. Dispos. 2008, 6, 995-1002. 
122. Youdim, K.A.; Qaiser, M.Z.; Begley, D.J.; Rice-Evans, C.A.; Abbott, N.J. Flavonoid permeability across an in situ model of the blood-brain barrier. Free Radic. Biol. Med. 2004, 5, 592-604.

123. Dagenais, C.; Graff, C.L.; Pollack, G.M. Variable modulation of opioid brain uptake by P-glycoprotein in mice. Biochem. Pharmacol. 2004, 2, 269-276.

124. Zhao, R.; Kalvass, J.C.; Pollack, G.M. Assessment of blood-brain barrier permeability using the in situ mouse brain perfusion technique. Pharm. Res. 2009, 7, 1657-1664.

125. Chen, W.; Yang, J.Z.; Andersen, R.; Nielsen, L.H.; Borchardt, R.T. Evaluation of the permeation characteristics of a model opioid peptide, H-Tyr-D-Ala-Gly-Phe-D-Leu-OH (DADLE), and its cyclic prodrugs across the blood-brain barrier using an in situ perfused rat brain model. J. Pharmacol. Exp. Ther. 2002, 2, 849-857.

126. Dagenais, C.; Zong, J.; Ducharme, J.; Pollack, G.M. Effect of mdrla P-glycoprotein gene disruption, gender, and substrate concentration on brain uptake of selected compounds. Pharm. Res. 2001, 7, 957-963.

127. Stevenson, I.H. Factors influencing antipyrine elimination. Br. J. Clin. Pharmacol. 1977, 3, 261-265.

128. O’Neil, M.J. The Merck Index: An Encyclopedia of Chemicals, Drugs, and Biologicals; Merck: Whitehouse Station, NJ, USA, 2001.

129. Ullrich, K.J.; Rumrich, G. Renal contraluminal transport systems for organic anions (paraaminohippurate, PAH) and organic cations (N1-methyl-nicotinamide, NMeN) do not see the degree of substrate ionization. Pflugers Arch. 1992, 2-3, 286-288.

130. Martin, A.N. Physical Pharmacy, 2nd Ed.; Lea \& Febiger: Philadelphia, PA, USA, 1969; Volume 1.

131. Streng, W.H. Microionization constants of commercial cephalosporins. J. Pharm. Sci. 1978, 5, 666-669.

132. Tomlinson, E.; Hafkenscheid, T.L. Aqueous solution and partition coefficient estimation from HPLC data. In Partition Coefficient, Determination and Estimation; Dunn, W.J., Block, J.H., Pearlman, R.S., Eds.; Pergamon Press: New York, NY, USA, 1986; Volume 1, pp. 101-141.

133. Sangster, J. Octanol-Water Partition Coefficients: Fundamentals and Physical Chemistry, 1st ed.; Wiley: New York, NY, USA, 1994; Volume 1.

134. McLure, J.A.; Miners, J.O.; Birkett, D.J. Nonspecific binding of drugs to human liver microsomes. Br. J. Clin. Pharmacol. 2000, 5, 453-461.

135. Deak, K.; Takacs-Novak, K.; Tihanyi, K.; Noszal, B. Physico-chemical profiling of antidepressive sertraline: Solubility, ionisation, lipophilicity. Med. Chem. 2006, 4, 385-389.

136. El Tayar, N.; van de Waterbeemd, H.; Testa, B. Lipophilicity measurements of protonated basic compounds by reversed-phase high-performance liquid chromatography: II. Procedure for the determination of a lipophilic index measured by reversed-phase high-performance liquid chromatography. J. Chromatogr. 1985, 2, 305-312.

137. Blum, W.; Phelps, M.A.; Klisovic, R.B.; Rozewski, D.M.; Ni, W.; Albanese, K.A.; Rovin, B.; Kefauver, C.; Devine, S.M.; Lucas, D.M.; et al. Phase I clinical and pharmacokinetic study of a novel schedule of flavopiridol in relapsed or refractory acute leukemias. Haematologica 2010, 7 , 1098-1105. 
138. Ronfeld, R.A.; Tremaine, L.M.; Wilner, K.D. Pharmacokinetics of sertraline and its $N$-demethyl metabolite in elderly and young male and female volunteers. Clin. Pharmacokinet. 1997, 32, 22-30.

139. Bres, J.; Bressolle, F. Pharmacokinetics of sulpiride in humans after intravenous and intramuscular administrations. J. Pharm. Sci. 1991, 12, 1119-1124.

140. Scavone, J.M.; Blyden, G.T.; Greenblatt, D.J. Lack of effect of influenza vaccine on the pharmacokinetics of antipyrine, alprazolam, paracetamol (acetaminophen) and lorazepam. Clin. Pharmacokinet. 1989, 3, 180-185.

141. Scavone, J.M.; Greenblatt, D.J.; Abernethy, D.R.; Luna, B.G.; Harmatz, J.S.; Shader, R.I. Influence of oral contraceptive use and cigarette smoking, alone and together, on antipyrine pharmacokinetics. J. Clin. Pharmacol. 1997, 5, 437-441.

142. Thompson, G.A.; St Peter, J.V.; Heise, M.A.; Horowitz, Z.D.; Salyers, G.C.; Charles, T.T.; Brezovic, C.; Russell, D.A.; Skare, J.A.; Powell, J.H. Assessment of doxylamine influence on mixed function oxidase activity upon multiple dose oral administration to normal volunteers. J. Pharm. Sci. 1996, 11, 1242-1247.

143. Rumble, R.H.; Roberts, M.S.; Scott, A.R. The effects of posture on the pharmacokinetics of intramuscular benzylpenicillin. Eur. J. Clin. Pharmacol. 1988, 6, 629-635.

144. Birkett, D.J.; Miners, J.O. Caffeine renal clearance and urine caffeine concentrations during steady state dosing. Implications for monitoring caffeine intake during sports events. Br. J. Clin. Pharmacol. 1991, 4, 405-408.

145. Brogard, J.M.; Pinget, M.; Dorner, M.; Lavillaureix, J. Determination of cefalexin pharmacokinetics and dosage adjustments in relation to renal function. J. Clin. Pharmacol. 1975, 10, 666-673.

146. Larsson, R.; Erlanson, P.; Bodemar, G.; Walan, A.; Bertler, A.; Fransson, L.; Norlander, B. The pharmacokinetics of cimetidine and its sulphoxide metabolite in patients with normal and impaired renal function. Br. J. Clin. Pharmacol. 1982, 2, 163-170.

147. Stuck, A.E.; Frey, F.J.; Heizmann, P.; Brandt, R.; Weidekamm, E. Pharmacokinetics and metabolism of intravenous and oral fleroxacin in subjects with normal and impaired renal function and in patients on continuous ambulatory peritoneal dialysis. Antimicrob. Agents Chemother. 1989, 3, 373-381.

148. Setchell, K.D.; Faughnan, M.S.; Avades, T.; Zimmer-Nechemias, L.; Brown, N.M.; Wolfe, B.E.; Brashear, W.T.; Desai, P.; Oldfield, M.F.; Botting, N.P.; et al. Comparing the pharmacokinetics of daidzein and genistein with the use of ${ }^{13} \mathrm{C}$-labeled tracers in premenopausal women. Am. J. Clin. Nutr. 2003, 2, 411-419.

149. Hughes, I.E.; Ilett, K.F.; Jellett, L.B. The distribution of quinidine in human blood. Br. J. Clin. Pharmacol. 1975, 6, 521-525.

150. Verme, C.N.; Ludden, T.M.; Clementi, W.A.; Harris, S.C. Pharmacokinetics of quinidine in male patients. A population analysis. Clin. Pharmacokinet. 1992, 6, 468-480.

(C) 2014 by the authors; licensee MDPI, Basel, Switzerland. This article is an open access article distributed under the terms and conditions of the Creative Commons Attribution license (http://creativecommons.org/licenses/by/3.0/). 